\title{
Guarrazar: el taller orfebre visigodo
}

\author{
Óscar García-Vuelta y Alicia Perea \\ Instituto de Historia \\ Centro de Ciencias Humanas y Sociales \\ Consejo Superior de Investigaciones Científicas \\ oscar.gvuelta@cchs.csic.es \\ alicia.perea@cchs.csic.es
}

\section{RESUMEN}

El estudio tecnológico y arqueométrico de los tesoros de Guarrazar y Torredonjimeno aporta nuevos datos para la caracterización del taller orfebre visigodo en la Península Ibérica hacia los siglos VII-VIII. El estudio conjunto de las materias primas, las técnicas y herramientas de fabricación, y las alteraciones experimentadas por estos materiales añade también nueva información para la interpretación de estos hallazgos, cuya tecnología valoramos en el contexto de la tradición orfebre mediterránea de la Antigüedad.

Palabras clave: Orfebrería visigoda, Tesoro de Guarrazar, Tesoro de Torredonjimeno, arqueometría, arqueometalurgia, tecnología.

\section{Guarrazar: The Visigothic Goldsmith Workshop}

\begin{abstract}
The technological and archaeometric study of the Guarrazar and Torredonjimeno treasures provide new data about the characterization of the visigothic goldsmith workshops in the Iberian Peninsula ca. VIIVIII Centuries. The joint study of the raw materials (gemstones and metals), working tools and techniques, as well as that on alterations of materials, adds new data for the archaeological interpretation of these finds, whose technology is assessed within the context of the Ancient Mediterranean goldwork tradition.
\end{abstract}

Key words: Visigothic jewelry, Guarrazar Treasure, Torredonjimeno Treasure, Archaeometry, Archaeometallurgy, Technology. 


\section{Introducción}

El tesoro de Guarrazar (Guadamur, Toledo), descubierto en 1858, es el principal exponente de la orfebrería visigoda del s. VII-VIII a nivel europeo, y el hallazgo que más ha influido en los estudios sobre esa materia en España ${ }^{1}$. Sin embargo, su azarosa biografía, bien estudiada por otros autores ${ }^{2}$, había afectado negativamente a su investigación, especialmente desde el punto de vista técnico, implicando la destrucción de muchos de los objetos descubiertos, la alteración de los conservados, y su dispersión. En la práctica, los complejos avatares del conjunto no concluyeron hasta 1943, con su reparto definitivo entre el Musée du Moyen Âge de Cluny, el Museo Arqueológico Nacional (MAN), y la Real Armería del Palacio Real (Figs. 1a y 1b).

Los problemas para su investigación se iniciaron ya a mediados del s. XIX. Por estos momentos, la venta del más importante lote de piezas al museo de Cluny ${ }^{3}$ y la recuperación de nuevos objetos en España ${ }^{4}$, dio paso a un período de actuaciones judiciales, investigaciones y reclamaciones oficiales. En ese contexto se publicaron los primeros estudios, que intentaron interpretar un hallazgo ya alterado, e incorporaron valoraciones poco objetivas, que se transmitieron sin ser adecuadamente contrastadas $^{5}$. La situación se agravó en la primera mitad del s. XX, tras los robos en 1921 y 1936 de parte de los materiales ingresados en el Palacio Real en 1861 (Fig. 1b) ${ }^{6}$. Desde entonces, se carecía de una revisión actualizada de los materiales de este conjunto, centrándose mayoritariamente las interpretaciones a nivel técnico en una valoración de la influencia bizantina en su concepción y ornamentación?

El conjunto de Torredonjimeno, descubierto en 1926 en el paraje de la Majada de Garañón (Torredonjimeno, Jaén), está considerado como un conjunto gemelo al de Guarrazar, y por la tipología de sus materiales (cruces de diferentes tipos, restos de coronas, colgantes y restos de vajilla, entre otros), constituye un ejemplo excepcional para su comparación a nivel tecnológico. Sin embargo, su biografía también ofrece

1 J.A. MORÁIS, "El descubrimiento del tesoro de Guarrazar como dinamizador de los estudios sobre arte hispanovisigodo en la España del siglo XIX", Perspectives contemporaines sur le monde médiéval. Actes du I Colloque International, Piteşti, 2009, pp. 260-266.

2 L. BALMASEDA, "De la historia del hallazgo y la arqueología de Guarrazar", A. PEREA (ed.), El tesoro visigodo de Guarrazar, Madrid, 2001, pp. 63-117.

3 F. DE LASTEYRIE, Description du Trésor de Guarrazar, accompagnée des recherches sur toutes les questions archéologiques qui s'y rattachent, París, 1860.

4 J.D. DE LA RADA Y DELGADO, "Coronas de Guarrazar que se conservan en la Real Armería de Madrid”, Museo Español de Antigüedades, 3 (1874), pp. 113-132.

5 Como las relativas al mal estado de conservación original de las piezas, o a la dificultad para su interpretación tras las excesivas intervenciones del orfebre J. Navarro. Sobre estas cuestiones véase A. PEREA, "De los talleres y los orfebres", A. PEREA (ed.), op. cit., 2001, pp. 123-127.

6 M. RUIZ CABRERA, "El tesoro de Guarrazar en el Palacio Real: historia y documentos", Reales sitios, 191 (2012), pp. 4-21; L. BALMASEDA, op. cit., 2001, p. 77.

7 J. AMADOR DE LOS RÍOS Y SERRANO, El arte latino-bizantino y las coronas visigodas de Guarrazar. Ensayo histórico-crítico, Madrid, 1861; H. SCHLUNK, "Relaciones entre la Península Ibérica y Bizancio durante la época visigoda", Archivo Español de Arqueología, 60 (1945), pp. 177-204; y M.A. CORTÉS, "Influencias bizantinas", A. PEREA (ed.), op. cit., 2001, pp. 369-375. 
similitudes con la de Guarrazar, incluyendo la falta de datos sobre su composición original, y la alteración de las piezas conservadas ${ }^{8}$.

El conjunto (Fig. 2) está repartido actualmente entre el Museo de Arqueología de Cataluña (MAC); el Museo Arqueológico de Córdoba (MAECO); el Museo Arqueológico Nacional (MAN), ingresando en estas instituciones entre los años 30 y 40 , tras haber pasado por las manos de chamarileros, anticuarios o coleccionistas? Desde entonces, las dificultades para desentrañar los avatares de todos estos objetos han provocado dudas sobre la composición real del hallazgo. La dispersión y el alto grado de fragmentación de las piezas habían dificultado igualmente su estudio técnico e interpretativo.

\section{El Proyecto Guarrazar}

En 1995 iniciamos el Proyecto Guarrazar, un programa de investigación a largo plazo para el estudio de la tecnología de la orfebrería visigoda en la Península Ibérica, que a nivel teórico y metodológico se integró en el Proyecto $A U$, una estrategia de investigación centrada en el estudio tecnológico de la orfebrería peninsular, desde sus primeras manifestaciones hasta el final de la Antigüedad $^{10}$.

El proyecto contó con la participación de investigadores españoles, franceses y belgas, así como con la colaboración de varias instituciones y organismos oficiales de financiación ${ }^{11}$. Los trabajos realizados se estructuraron en dos fases: la primera se dedicó al estudio del conjunto de Guarrazar e hizo posible completar una revisión tecnológica de todos sus materiales y profundizar en diferentes aspectos de su investigación. Esta fase finalizó en 2001 $1^{12}$. La segunda fase del proyecto se inició en 2003 y estuvo orientada a la investigación del conjunto de Torredonjimeno. En este caso,

8 L. BALMASEDA, "Hallazgo y dispersión del conjunto de Torredonjimeno según la documentación del M.A.N.", A. PEREA (ed.), El tesoro visigodo de Torredonjimeno, Madrid, 2009, pp. 29-54.

9 Sobre el ingreso de las piezas en los diferentes museos véanse los trabajos de S. SANTOS GENER, "Un lote del tesorillo de orfebrería visigótica hallado en Torredonjimeno" entre otros, Anuario del Cuerpo Facultativo de Archiveros, Bibliotecarios y Arqueólogos, III (1935), pp. 379-403; M. ALMAGRO BASCH, "Los fragmentos del tesoro de Torredonjimeno, conservados en el Museo de Barcelona", Memorias de los Museos Arqueológicos Provinciales, 7 -año 1946-, Madrid, 1947, pp. 64-75; M. ALMAGRO BASCH, "Nuevos fragmentos del tesoro de Torredonjimeno (Jaén)", Memorias de los Museos Arqueológicos Provinciales, 9-10, Madrid, 1950, pp. 200-203; y L. BALMASEDA, op. cit., 2009, pp. 31-40.

10 I. MONTERO y A. PEREA, "El proyecto Guarrazar", La Mancha Occidental y la Mesa de Ocaña, I, Toledo, 2001, pp. 357-378; L. BALMASEDA y A. PEREA, "Las tres historias de Guarrazar y el Proyecto AU", Revista de Arqueología, 221 (1999), pp. 36-45; y A. PEREA, "Tecnología, política y sociedad: el Proyecto Au", Saguntum, 32 (2000), pp. 123-129.

11 Cabe destacar en primer lugar la colaboración de todos los museos que conservan las piezas. En 1997 y 1998 la Comunidad de Madrid, a través de su Consejería de Cultura, financió los proyectos de investigación Tecnología del Oro Visigodo: Guarrazar y Torredonjimeno (06/020/1997) y Aplicaciones analíticas e informáticas de un proyecto de investigación sobre tecnología visigoda: el tesoro de Guarrazar (CM 96/0094/1998). En 1997 y 1999 la Comisión Europea financió dos misiones científicas dentro de su programa COST, que facilitaron el estudio analítico de las piezas de Guarrazar. En el caso de Torredonjimeno, este trabajo se realizó en colaboración con el Centro de Microanálisis de Materiales (UAM).

12 A. PEREA (ed.), op. cit., 2001. 
se aprovechó la oportunidad brindada por la exposición Torredonjimeno: tesoro, monarquía y liturgia ${ }^{13}$, que reunió por primera vez todos sus materiales, para realizar un estudio integral de las piezas, aplicando los mismos planteamientos teórico-metodológicos considerados para Guarrazar. Los resultados de esta fase, finalizada en 2009, permitieron una completa revisión del hallazgo giennense, avanzar en distintas cuestiones de su investigación, y aportar un estudio comparativo entre ambos conjuntos ${ }^{14}$.

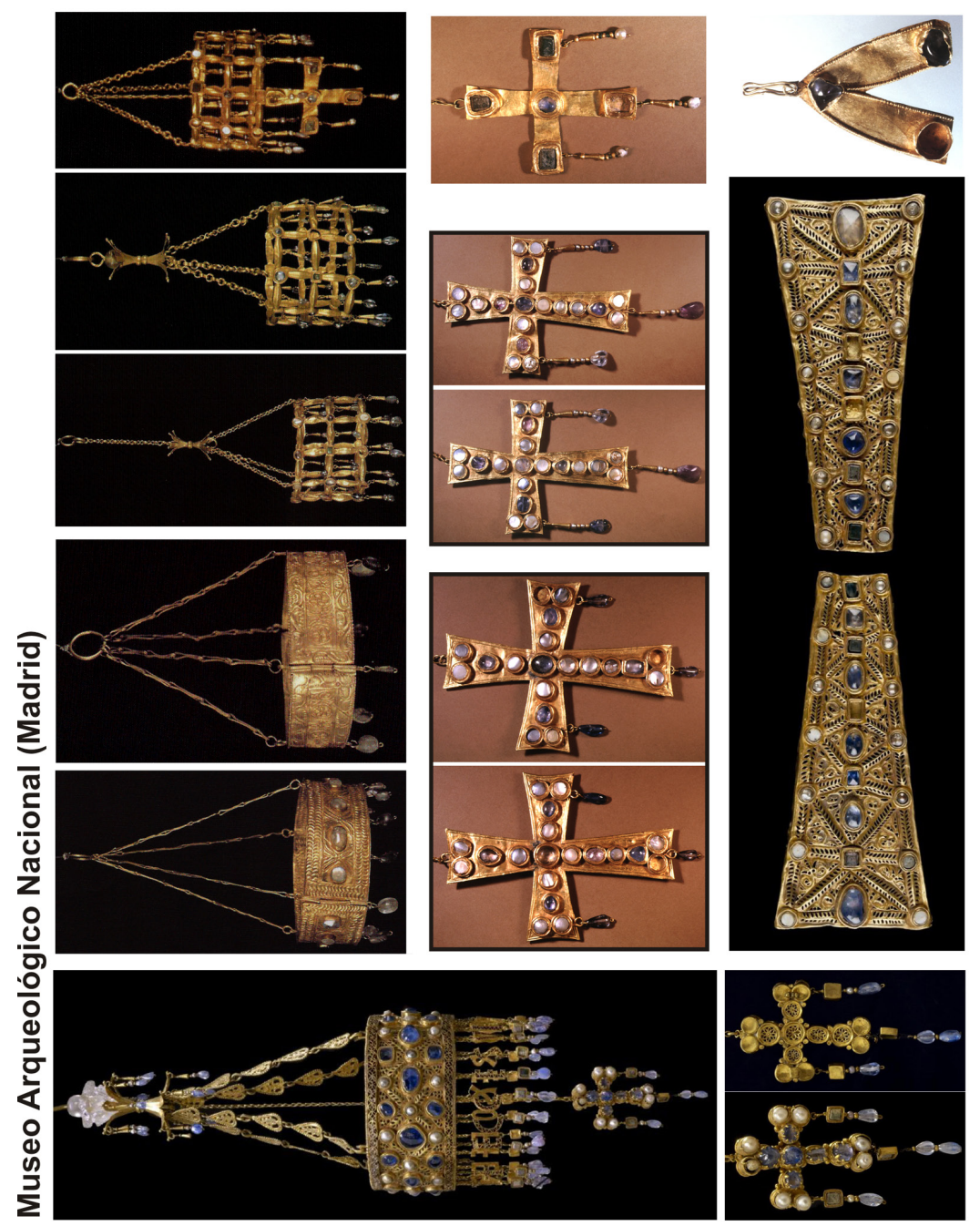

Fig. 1a. Guarrazar. Materiales conservados en el Museo Arqueológico Nacional. Fotos: Archivo Au, MCED.

13 A. CASANOVAS y J. ROVIRA I PORT (eds.), Torredonjimeno. Tesoro, monarquía y liturgia, Barcelona, 2003. Esta exposición se celebró entre 2003 y 2005, y contó con sedes en Córdoba, Barcelona, Jaén y Madrid.

14 A. PEREA (ed.), op. cit., 2009. 

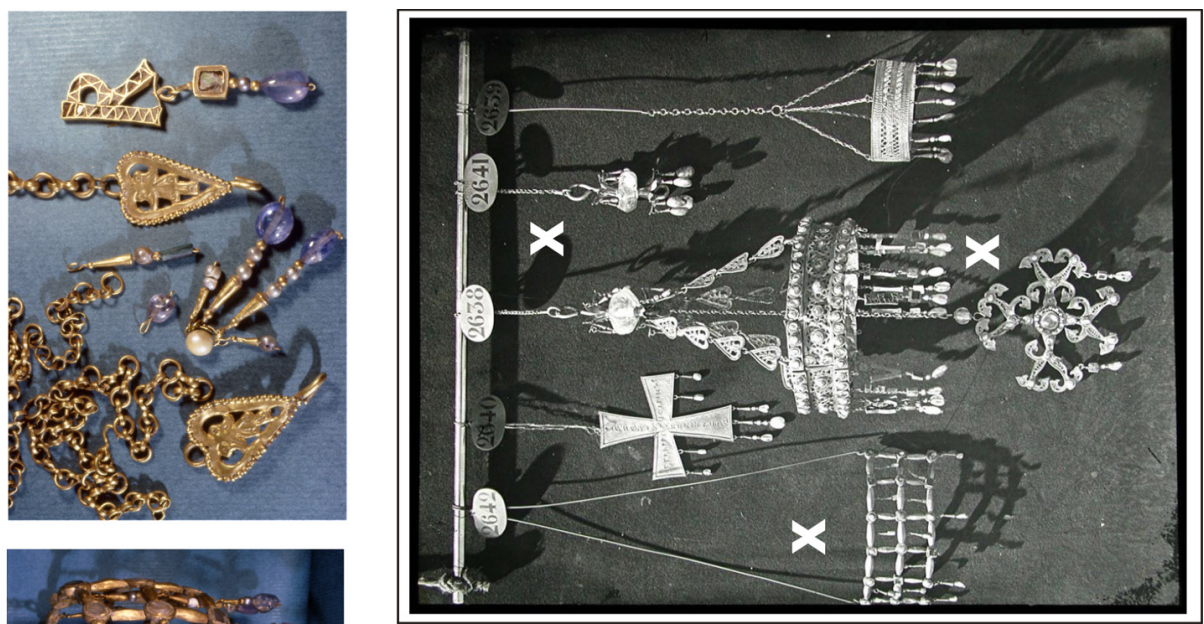

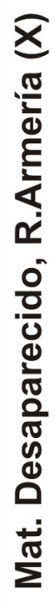
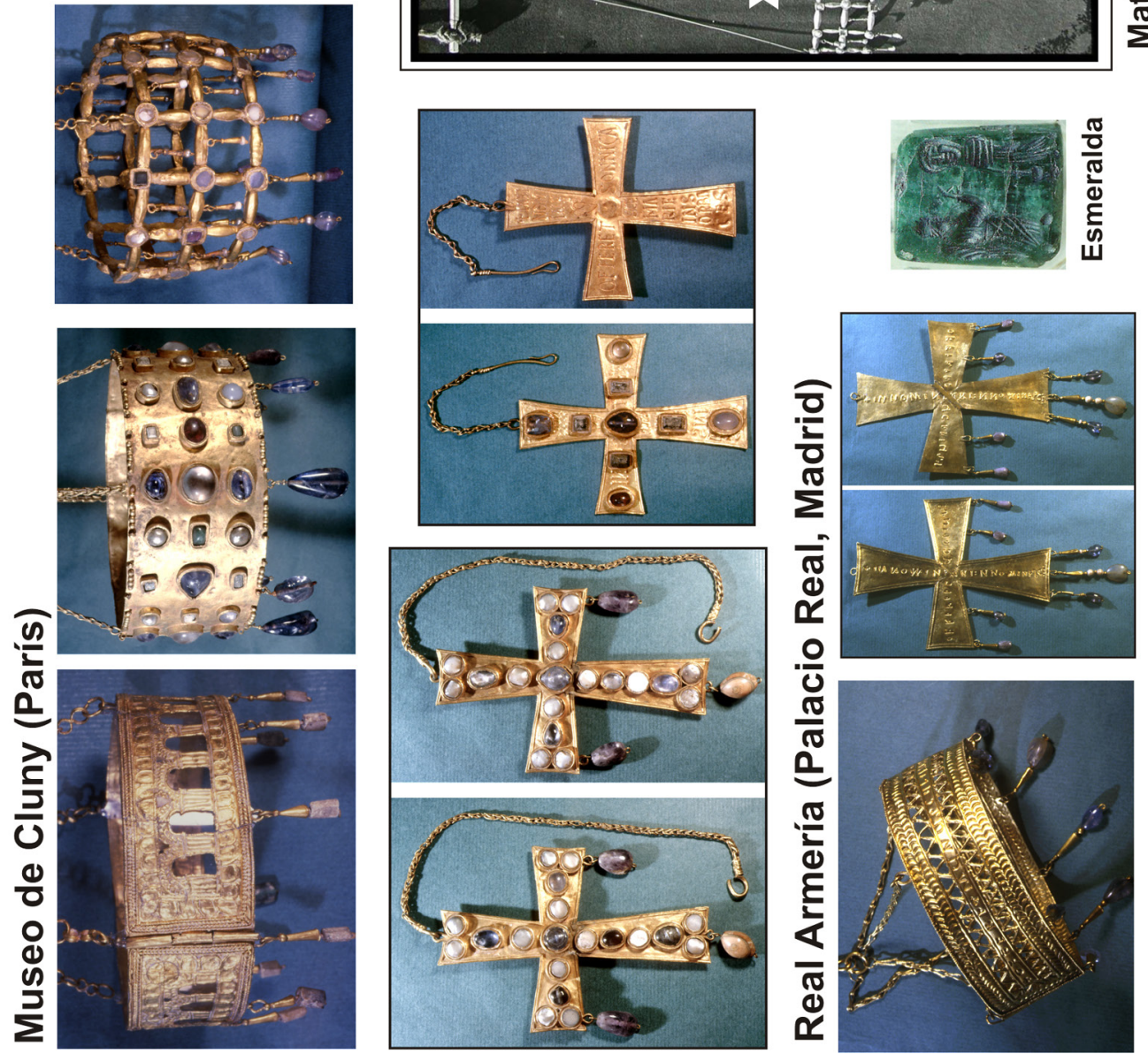

Fig. 1b. Guarrazar. Materiales conservados en el Museo de Cluny y Palacio Real, junto a las piezas desaparecidas de esta institución. Fotos: Archivo Au, MCED. 


\section{El estudio tecnológico}

Sin duda las mayores dificultades para el estudio de estos hallazgos se plantean a nivel interpretativo. Sin embargo, podemos mencionar dos cuestiones que en el caso de Guarrazar dificultaron la aplicación de una metodología de trabajo homogénea: la dispersión de los objetos ( $\mathrm{y}$ en el caso de Torredonjimeno, también su fragmentación), y los diferentes criterios establecidos por las instituciones responsables de su custodia, a los que nos referiremos más adelante.

\section{Dispersión de los conjuntos}

Desde 1943, la mayor parte de los materiales de Guarrazar se encuentra en el MAN (Fig. 1a), que conserva un total de 6 coronas (2 de lámina repujada y 3 de estructura calada reticulada, además de la corona de doble chapa con dedicación de Recesvinto); 4 cruces con engastes y colgantes (incluyendo la perteneciente a la corona de Recesvinto, que representa la única asociación fiable entre cruces y coronas); 2 revestimientos con engastes correspondientes a los brazos de una gran cruz; un colgante con engastes en forma de letra Alfa, posiblemente asociado a la anterior, y 2 fragmentos de cadenas, de ochos y de anillas. Completan el inventario restos de colgantes y cabujones (gemas, perlas y nácar), así como algunos fragmentos laminares de plata y cobre.

El Museo de Cluny conserva tres coronas ( 1 de chapa simple, otra de lámina repujada y recortada, y otra con estructura calada reticulada); 2 cruces con engastes, una de ellas con inscripción (cruz de Sonnica); 1 eslabón y un colgante con letra R, pertenecientes a la corona de Recesvinto; 1 cadena con eslabones en 8 y algunos restos de cadenas, colgantes y cabujones. Finalmente, la Real Armería conserva una corona repujada y calada con inscripción (corona de Teodosio); una cruz sin engastes con colgantes e inscripción (cruz de Lucecio), y una esmeralda tallada con escena de La Anunciación; tras los robos en 1921 y 1936 de la corona y la cruz del rey Suintila, una macolla correspondiente a otra corona, y una corona reticulada incompleta.

Los materiales de Torredonjimeno se reparten principalmente entre el MAC y el MAECO, y en menor medida en el MAN, y se conservan en su mayor parte muy fragmentados. Como se ha señalado, el conjunto, del que se muestran algunos ejemplos en la Fig. 2, está formado principalmente por restos de cruces, en su mayor parte incompletas, incluyendo cruces laminares lisas o decoradas; con engastes o tabicadas, entre otras (Fig. 2, A). Se documentan también cadenas, elementos de suspensión y numerosos restos de colgantes, correspondientes en su mayor parte a cruces y coronas, destacando los colgantes de letras tabicadas, que pertenecieron a coronas regias (Fig. 2, B), o un ejemplar con forma de Alfa, muy similar al documentado en Guarrazar (Fig. 2, C). El inventario se completa con restos de vajilla y otros fragmentos de interpretación funcional dudosa ${ }^{15}$.

15 Véase un inventario detallado de los materiales en A. PEREA (ed.), op. cit., 2009, pp. 19 y ss. 

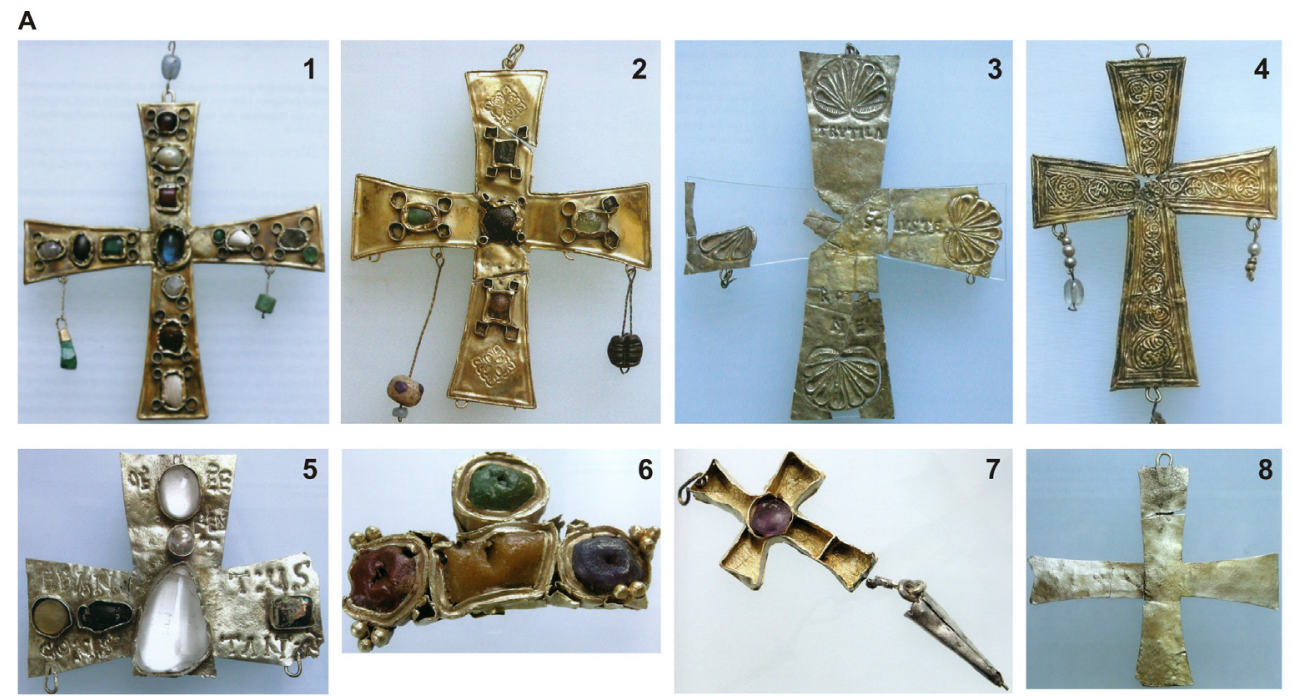

B
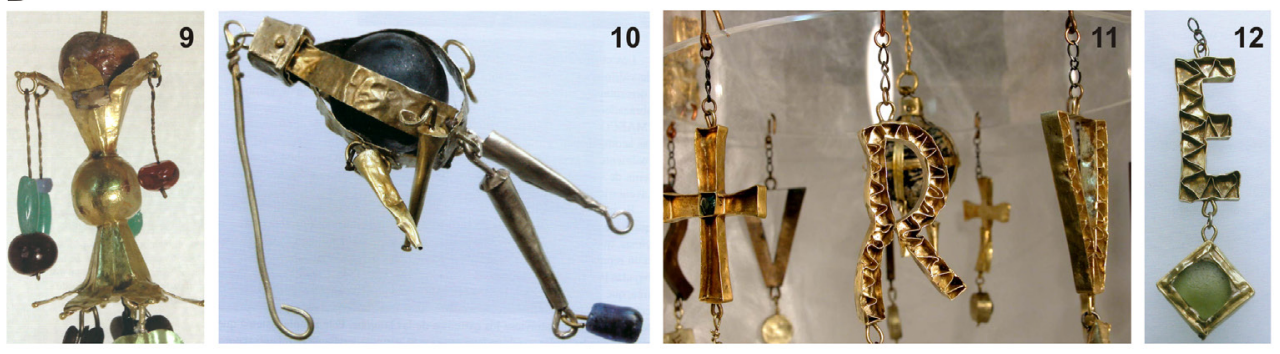

C
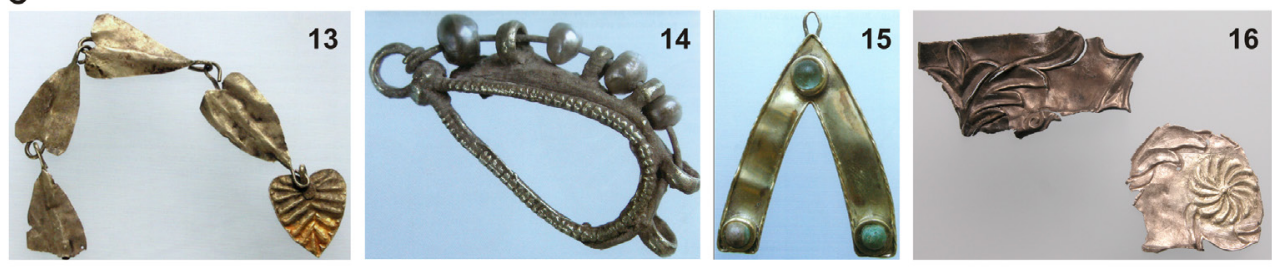

Fig. 2. Torredonjimeno: ejemplos de los principales tipos de materiales documentados:

A. Cruces. 1. Cruz con 12 engastes (MAC15070); 2. Cruz con 5 engastes, estampada (MAC25240); 3. Cruz repujada de Trutila (MAECO 29933); 4. Cruz repujada (MAECO 29919); 5. Fragmento con engastes e inscripción de Ebantius (MAC 25056); 6. Fragmento de cruz calada (30.690); 7. Cruz tabicada (MAC 30683b); 8. Cruz laminar lisa recompuesta (MAC 25084). B. Restos atribuibles a coronas: 9. Macolla con colgantes (MAC 25090); 10. Colgante con orbe (MAC 25242); 11. Cruces y letras tabicadas (MAC 25085); 12. Colgante tabicado letra E (MAC 15079). C. Elementos de suspensión, colgantes y vajilla: 13. Eslabones de cadena y un colgante en hoja (MAN 61192); 14. Colgante con forma de lágrima, de funcionalidad dudosa (MAECO s/n 17); 15. Colgante en Alfa, muy semejante al conservado en el tesoro de Guarrazar (MAC 25086); 16. Restos laminares decorados, correspondientes a vajilla (izquierda: MAECO 29996; derecha: MAC 25101). Fotos: Archivo Au. 


\section{Objetivos}

Los problemas existentes para la investigación arqueológica y tecnológica de estos hallazgos permitieron plantear unos objetivos de trabajo comunes.

1. Valorar el estado real de conservación de las piezas, para determinar hasta qué punto las alteraciones producidas en el yacimiento y/o durante las manipulaciones posteriores habían afectado a sus posibilidades de interpretación a nivel tecnológico y arqueológico.

2. Completar una revisión de todos los materiales conservados, considerando el estudio de las materias primas (metales y gemas) y de los procedimientos empleados en su elaboración como elementos clave para el conocimiento de su tecnología y la caracterización de los talleres de producción.

3. Aportar nuevas referencias para el estudio cronológico: las ocultaciones de Guarrazar y Torredonjimeno se han fechado a finales del s. VII, como respuesta al avance de la invasión musulmana. Sin embargo, carecíamos de información para valorar más detalladamente la homogeneidad o heterogeneidad cronológica de sus materiales, si exceptuamos, para el caso de Guarrazar, los datos aportados por las coronas de Suintila (621-631) y Recesvinto (649-672).

\section{Metodología}

El estudio se organizó fundamentalmente en dos fases. En primer lugar, una Fase Macroscópica, dedicada a la revisión topográfico de los objetos. En ella, se caracterizan las técnicas y procedimientos empleados en su fabricación y ornamentación; las posibles evidencias de desgaste por uso; los procesos de deterioro ocasionados durante su permanencia en el yacimiento; y las manipulaciones o alteraciones antiguas y recientes. Para estos estudios nos apoyamos principalmente en la revisión de los materiales mediante medios ópticos, empleando lupas binoculares de hasta X80 ${ }^{16}$. Todos los resultados de esta fase de trabajo se documentan mediante fotografía macro.

La Fase analítica amplía los resultados obtenidos en la fase macroscópica. Se centra en el estudio de la composición de los objetos, considerando las materias primas (metal y gemas) y las aleaciones empleadas en los procesos de fabricación. En esta fase se persigue también una caracterización más detallada de los procedimientos de fabricación y de las alteraciones sufridas por los materiales.

Entre los procedimientos de caracterización analítica no destructiva, optamos por las técnicas espectroscópicas con haz de iones, o técnicas IBA (Ion Beam Analysis) ${ }^{17}$. La técnica PIXE (Particle Induced X ray Emission), de gran precisión para el análisis cuantitativo de los elementos químicos más pesados, constituyó el procedimiento básico para el estudio de los objetos metálicos. La técnica PIGE (Particle Induced $\gamma$ ray

16 Los trabajos de la fase macroscópica se completan con una Fase Microscópica, que se apoya en el uso de herramientas de observación topográfica más potentes, como el microscopio electrónico de barrido (MEB). Las dificultades para el desplazamiento de las piezas de Guarrazar y su excesivo tamaño para su estudio en un MEB, hicieron que su uso se limitase a la revisión de algunas gemas, vidrios y pequeños fragmentos de oro.

17 G. DEMORTIER, "Ion Beam Study of archaeological gold jewelry items", Nuclear Instruments \& Methods B. Beam Interactions with Materials \& Atoms, 113 (1996), pp. 347-353. 
Emission), más eficaz para la cuantificación de elementos ligeros, se utilizó, en combinación con PIXE, para la caracterización de gemas y vidrios ${ }^{18}$.
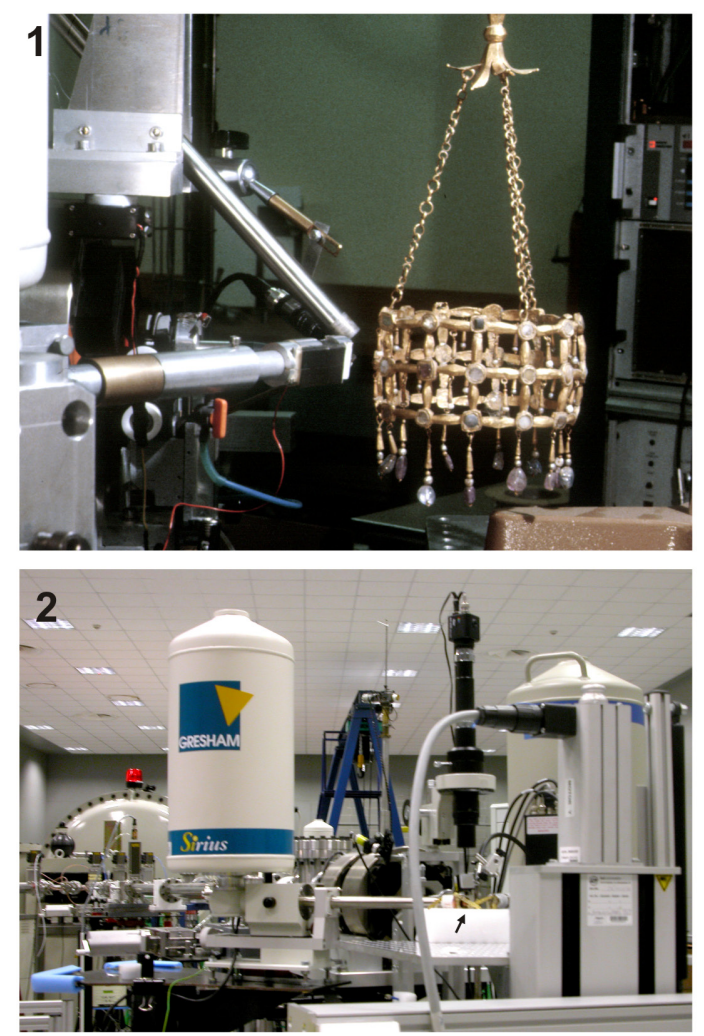

Fig. 3. 1. Análisis PIXE de la corona calada de Cluny en el LARN (Namur); 2. Línea de Microhaz externo del Acelerador de Partículas (CMAM, UAM), utilizada para el estudio de Torredonjimeno. Fotos: Archivo Au.

Se trata de unas técnicas de gran precisión cuantitativa, que facilitan el estudio de los objetos en condiciones ambientales, independientemente de su forma o tamaño. Sin embargo, también ofrecen inconvenientes, pues los aceleradores de partículas con los que se generan los haces de iones requieren grandes instalaciones, lo que implica trasladar las muestras al laboratorio. Esto dificultó la aplicación de una metodología de trabajo homogénea, debido a los diferentes criterios establecidos por los museos. El MAN no permitió el desplazamiento de sus materiales, aunque sí la extracción de micromuestras de oro que se analizaron por PIXE en el Laboratoire d'analyses par Réactions Nucleaires (Univ. Notre Dâme-de-la-Paix, Namur, Bélgica). Las gemas y

18 A. CLIMENT-FONT et al., "Estudio arqueométrico mediante técnica PIXE", A. PEREA (ed.), op. cit., 2009 , pp. 201 y ss. 
vidrios de las piezas del MAN se estudiaron en su mayor parte con medios ópticos ${ }^{19}$. El Museo de Cluny permitió el desplazamiento de sus piezas, que fueron analizadas por PIXE y PIGE (Fig. 3, 1) en el Centre de Recherche et de Restauration des Musées de France (París) ${ }^{20}$. Finalmente, el Palacio Real no permitió el desplazamiento ni la extracción de muestras, por lo que el estudio analítico se desarrolló en sus propios laboratorios, mediante Fluorescencia de rayos X (FRX $)^{21}$.

En el caso de Torredonjimeno, todos los análisis PIXE y PIGE se realizaron en el Centro de Microanálisis de Materiales de la Universidad Autónoma de Madrid (Fig. $3,2)$. Sin embargo, solo pudieron aplicarse a una muestra representativa del conjunto, pues las posibilidades de traslado de las piezas se vieron limitadas por la necesidad de su exhibición en la exposición ${ }^{22}$.

\section{Conclusiones biográficas}

El estudio de Guarrazar permitió verificar que las piezas se encontraban en buen estado en el momento del hallazgo, y que la mayor parte de las alteraciones se produjeron posteriormente. Las más agresivas se realizaron durante el desmontaje de los objetos por parte de los descubridores y de los plateros que los adquirieron inicialmente. Estas actuaciones ocasionaron graves deformaciones y fracturas, así como la pérdida de buena parte de los elementos originales de las piezas (gemas, engastes, colgantes o cadenas), para facilitar su venta o su fundición (Fig. 4, 1).

Los materiales que han llegado hasta nuestros días parecen ser, sin embargo, los mejor conservados. Esto habría propiciado que J. Navarro, orfebre de gran experiencia, advirtiese sus buenas posibilidades de reconstrucción, procediendo a la reparación de roturas y deformaciones (Fig. 4, 2), o a la restitución o la sustitución de muchos de los elementos originales alterados (p. ej. engastes de la corona de Recesvinto). A pesar del alcance y el carácter invasivo de estas intervenciones, pueden considerarse en su conjunto como relativamente respetuosas, y estuvieron orientadas a restituir el aspecto original de las piezas, aunque fuesen realizadas para aumentar su valor de mercado.

Finalmente, se documentaron algunas intervenciones y reparaciones producidas tras el ingreso de los objetos en los museos, como las observables en la corona de Recesvinto, o en la corona con arcos de Cluny.

19 Véase J.S. CÓZAR y C. SAPALSKI, “Gemas del Museo Arqueológico y el Palacio Real, Madrid”, A. PEREA (ed.), op. cit., 2001, pp. 247-271.

20 T. CALLIGARO, J.C. DRAN y J.P. POIROT, “Estudio por acelerador de las gemas del Museo Nacional de la Edad Media, Cluny”, A. PEREA (ed.), op. cit., 2001, pp. 207-293.

21 I. MONTERO et al., "Del estudio analítico del oro", A. PEREA (ed.), op. cit., 2001, pp. 205-237.

22 A. CLIMENT-FONT et al., op. cit., 2009, pp. 207 y ss. 

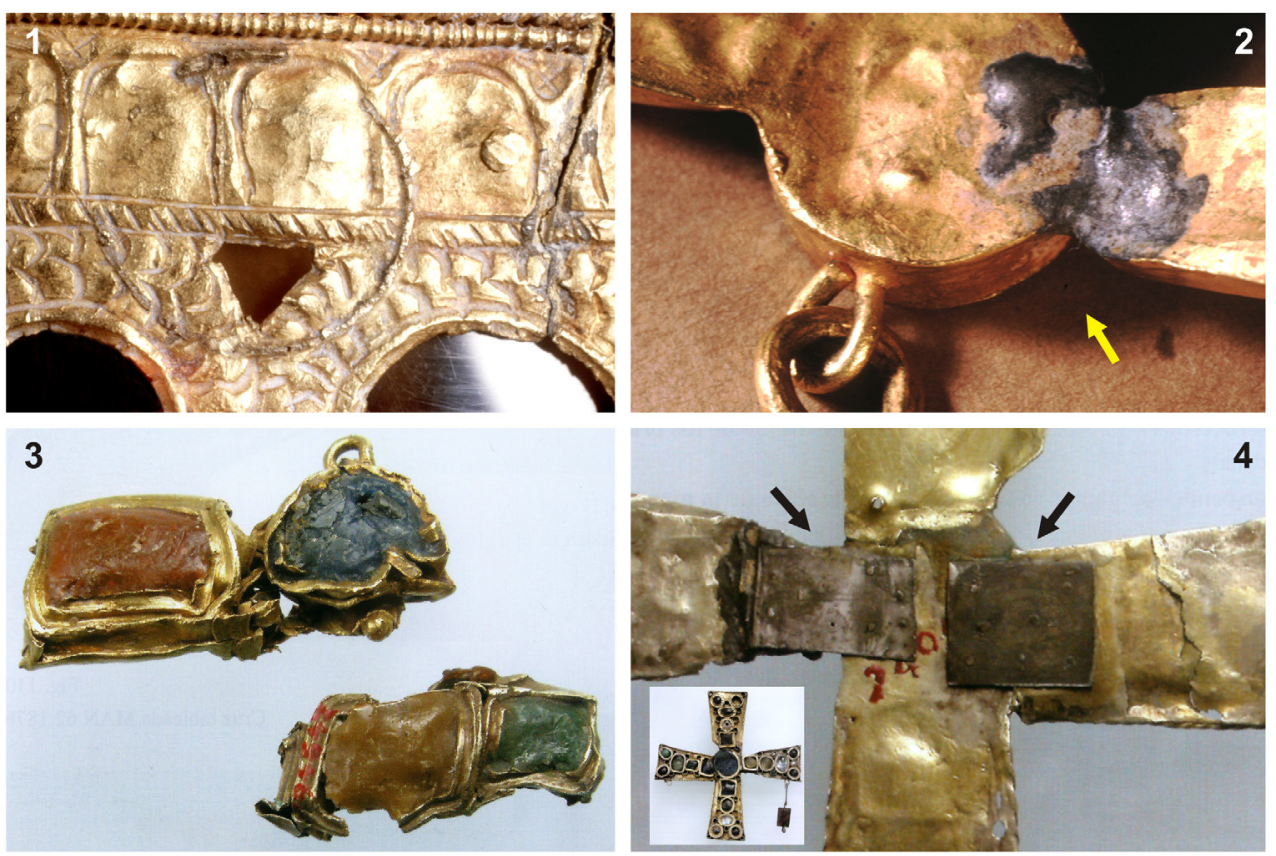

Fig. 4. Alteraciones. Guarrazar: 1. Huella circular correspondiente a la soldadura de un engaste arrancado en la corona repujada con arcos (Cluny 2885); 2. Reparación con soldadura de la corona reticulada (MAN 71208); Torredonjimeno: 3. Relleno con ceras simulando chatones en un fragmento de cruz calada (MAC 24224 a-b); 4. Recomposición de una cruz con fragmentos de ejemplares diferentes, unidos con soldaduras de placas metálicas por el reverso (MAC 25090). Fotos Archivo Au.

El conjunto de Torredonjimeno ofrece peor estado de conservación. El estudio de las zonas de fractura de las láminas evidenció que en muchos casos estas se habían producido ya de forma previa a la ocultación ${ }^{23}$, observándose pátinas generadas en el propio yacimiento. Se observan también numerosas fracturas y alteraciones provocadas posteriormente. Las alteraciones más agresivas se realizaron para incrementar el valor de mercado de los objetos; por ejemplo, la soldadura o remachado de placas metálicas para recomponer fragmentos (Fig. 4, 4), o la limpieza abrasiva de las piezas, que ha eliminado buena parte de las pátinas originales. Se documentan igualmente otras intervenciones "menores" como el empleo de pegamentos o el relleno de engastes con cera coloreada para simular gemas (Fig. 4, 3) ${ }^{24}$.

23 No se han obtenido datos fiables sobre la conservación original de este conjunto. Sin embargo, se había sugerido - por comparación con el tesoro de Guarrazar- que las piezas podrían haber aparecido completas en el momento de su hallazgo. Véase M. ALMAGRO, op. cit., 1946 [1947], pp. 64-65.

24 A. PEREA, "Interpretación tecnómica", A. PEREA (ed.), op. cit., 2009, p. 59. 


\section{La naturaleza de los hallazgos}

Los estudios realizados aportan información sobre las características de las ocultaciones de ambos conjuntos, e indican que probablemente nos encontramos ante hallazgos de diferente naturaleza. Guarrazar puede caracterizarse como la ocultación planificada de un conjunto de objetos con un especial valor simbólico y económico, formado por piezas completas y probablemente en uso en el momento de la ocultación. Aunque la mayor parte de los materiales recuperados pertenecen a objetos votivos, con donaciones reales y de personajes de alto rango, la documentación conservada indica que también incorporaba material litúrgico, por lo que su caracterización como el ajuar procedente de una iglesia o lugar sagrado parece la más adecuada.

La ocultación de Torredonjimeno presenta características muy diferentes, pues el conjunto incorporó tanto piezas completas como objetos ya fragmentados. Sus semejanzas tipológicas con Guarrazar; las numerosas dedicaciones documentadas, y los restos de coronas, interpretables como posibles donaciones reales, evidencian que también nos encontramos ante materiales de especial valor simbólico y económico. Como indican las inscripciones conservadas con mención a Sta. Justa y Sta. Rufina, buena parte de estos materiales pudieron proceder de un mismo recinto sagrado. Sin embargo, el hallazgo parece caracterizar un expolio, en el que independientemente de su procedencia o significado original, las piezas se ocultaron en función de su valor material.

\section{Conclusiones técnicas y analíticas. Las materias primas}

\section{Los metales}

La materia prima empleada en Guarrazar fue el oro aleado $(\mathrm{Au} / \mathrm{Ag} / \mathrm{Cu})^{25}$. Destaca la heterogeneidad de las aleaciones documentadas. Las de mayor pureza superan el $90 \%$ de oro, y llegan a alcanzar en un caso hasta un 98\% (Letra $R$ de Cluny). En el extremo opuesto, encontramos aleaciones con ca. $62 \%$ de oro, existiendo también un amplio rango de composiciones intermedias, identificándose hasta cuatro grupos de composición, definidos por la presencia de plata (Fig. 5) ${ }^{26}$.

Los resultados indican una tendencia a la relación directa entre la mayor pureza de la aleación y la mayor calidad de ejecución técnica del objeto. Por ejemplo, la corona regia de Recesvinto y su cruz asociada, las piezas más complejas, pertenecen al grupo de aleaciones con mayor contenido en oro (grupo 1). En el extremo opuesto (grupo

25 A. PEREA et al., "The Guarrazar treasure (Toledo, Spain). Visigothic goldwork and gemstones of the 7th century", A. ADRIAENS, CH. DEGRIGNY y J. CASSAR (eds.), Benefits on non-destructive analytical techniques for conservation, Luxemburgo, 1996, pp. 59-69; A. PEREA e I. MONTERO, "Guarrazar, aproximación al tesoro y primeros análisis”, Boletín de Arqueología Medieval, 11 (1997), pp. 237-247; I. MONTERO et al., op. cit., 2001, pp. 201-237.

26 I. MONTERO et al., op. cit., 2001, pp. 222 y ss. 
4) encontramos objetos técnicamente más simples, como las dos coronas de lámina repujada del MAN, o la cruz de Lucecio, del Palacio Real.

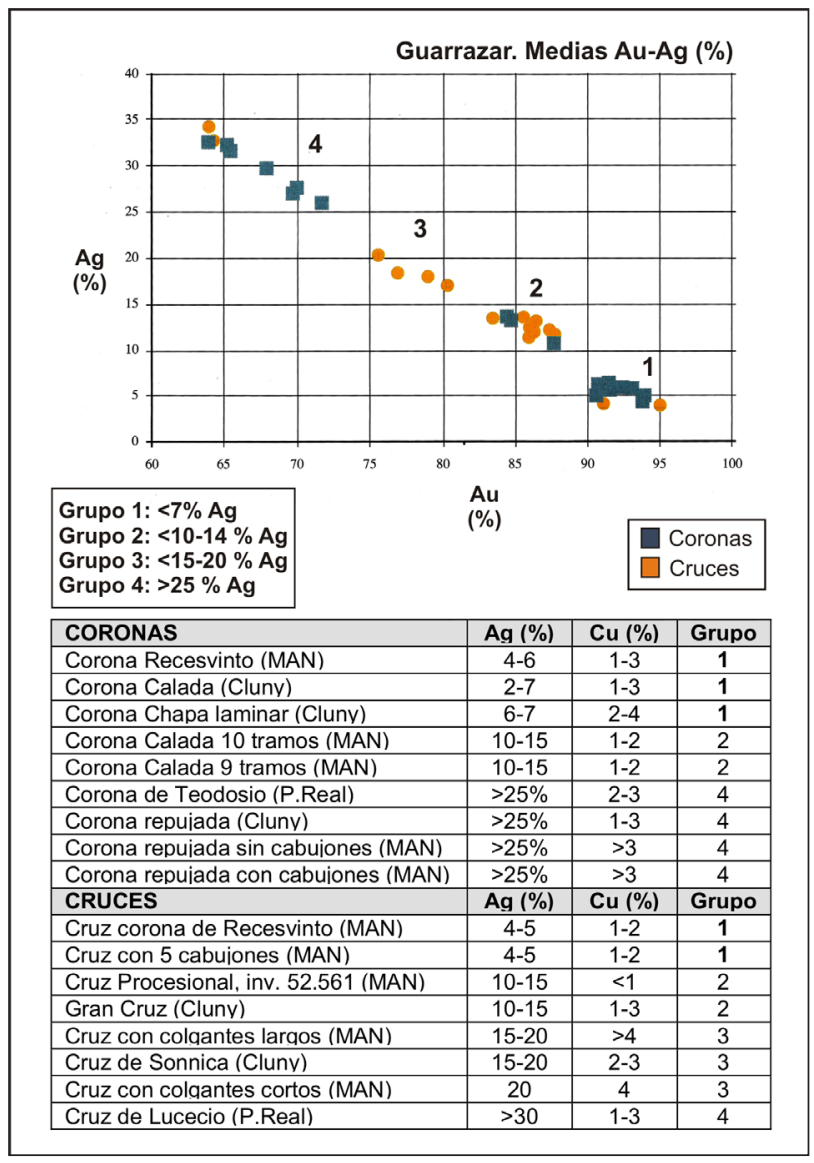

Fig. 5. Resultado de los análisis de las láminas de base de los objetos de Guarrazar. Grupos de composición identificados en función de la presencia de plata en la aleación. Valores normalizados y expresados en \% de peso. Según I. MONTERO et al, op. cit., 2001, pp. 221-222.

Otro rasgo a destacar es que no existe una relación entre la composición de estos materiales y la del monetario en oro de la época. El análisis PIXE-PIGE verificó que las piezas de Guarrazar - generalmente con contenidos de Au entre el $85 \%$ y el $95 \%$ - presentan una mayor pureza de oro que el material numismático ${ }^{27}$, incluso ex-

27 M.F. GUERRA, A. PEREA y T. CALligARO, "Coins and crowns. A first approach to the gold characterization of the treasure of Guarrazar (Toledo, Spain)", A. PEREA, I. MONTERO y O. GARCÍAVUELTA (eds.), Tecnología del oro antiguo: Europa y América, Anejos de Archivo Español de Arqueología, XXXII, Madrid, 2004, pp. 417-422; M.F. GUERRA, T. CALLIGARO y A. PEREA, "The treasure of Guarrazar: tracing the gold supplies in the visigothic Iberian Peninsula", Archaeometry, 49 (2007), pp. 53-74. 
cluyendo de la muestra de comparación las monedas más devaluadas, acuñadas por los últimos reyes visigodos -tremisses- que no superan el $75 \%$ de oro ${ }^{28}$.

Finalmente, hay que señalar que el estudio analítico de Guarrazar permitió también diferenciar muchas de las recomposiciones realizadas en el s. XIX, caracterizar las reparaciones, e identificar la sustitución de elementos originales áureos con otros que simulan esta apariencia ${ }^{29}$.

En el caso de Torredonjimeno ${ }^{30}$ observamos una mayor heterogeneidad de las aleaciones, predominando por lo general unos oros más devaluados, aunque en algún caso también se documentan oros de mayor pureza, como el utilizado en algunas de las letras tabicadas. Sin embargo, el principal aspecto a destacar es la alta presencia de piezas de plata dorada, empleándose para este fin la técnica del dorado por amalgama con mercurio ${ }^{31}$.

El estudio de las materias primas metálicas de ambos conjuntos evidencia importantes diferencias de taller y señala la mayor dificultad a los recursos por parte de los orfebres de Torredonjimeno, cuyas piezas parecen haber sido concebidas para un espectro social más amplio que las del conjunto toledano.

\section{Gemas y vidrios}

Una de las principales características a destacar en Guarrazar es el predominio del uso de gemas naturales frente al de vidrios sintéticos, así como la variedad de estas gemas. Los tipos mejor representados son el zafiro azul; la perla y el nácar, así como el granate, conservándose numerosos fragmentos. Se identifica también el uso de cuarzo amatista; esmeralda; cuarzo hialino; calcedonias azules y marrones; cordierita-iolita; adularia y aguamarina ${ }^{32}$.

El segundo factor a destacar es la diversidad de las procedencias. Se ha establecido que los zafiros y granates proceden de Sri-Lanka, y que 11 de las 14 esmeraldas identificadas proceden de las minas de Habachtal, en Austria ${ }^{33}$. Establecer la procedencia

28 M.F. GUERRA et al., op. cit., 2004, p. 420; M.F. GUERRA et al., op. cit., 2007, pp. 62-64. El análisis PIXE-PIGE se ha empleado también para anotar las primeras hipótesis sobre la procedencia de los oros empleados. Los datos obtenidos parecen indicar un uso principal de materias primas locales, procedentes probablemente del Sur peninsular, aunque esta información deberá confirmarse en el futuro con nuevos datos comparativos. Sobre estos estudios véase M.F. GUERRA et al., op. cit., 2007, p. 70.

29 Por ejemplo, el uso de latón en proporciones coincidentes con el denominado Metal de Hamilton (67\% $\mathrm{Cu}$ y ca. 30-35\% Zn), también conocido como oro musivo por su coloración semejante a la del oro, cuyo uso tuvo gran difusión en el s. XIX.

30 A. PEREA et al., "The visigothic treasure of Torredonjimeno (Jaén, Spain): A study with IBA techniques", Nuclear Instruments \& Methods in Physics Research B, 249 (2008), pp. 638-641; A. CLIMENTFONT et al., op. cit., 2009, pp. 207 y ss.

31 Sobre esta técnica véase entre otros J. BARRIO y J. CHAMON (eds.), Proyecto dorados. Tecnología, conservación y restauración de los metales dorados medievales, Madrid, 2010. Sobre su uso en Torredonjimeno véase A. PEREA, "Un taller de orfebrería visigodo en la Bética”, A. PEREA (ed.), op. cit., 2009, pp. 191 y ss.

32 J.S. CÓZAR y C. SAPALSKI, "Estudio de los materiales gemológicos del tesoro de Guarrazar", Boletín del Instituto Gemológico Español, 37 (1996), pp. 5-18; J.S. CÓZAR y C. SAPALSKI, op. cit., 2001, pp. 243273; T. CALLIGARO, J.C. DRAN y J.P. POIROT, op. cit., 2001, pp. 277-286.

33 T. CALLIGARO, et al., "El enigmático origen de las esmeraldas del tesoro", A. PEREA (ed.), op. cit., 2001, pp. 289-294. 
de los demás materiales es más dificultoso ${ }^{34}$, aunque para cuarzos, amatistas, perlas y nácar podría apuntarse un origen oriental (Mar Rojo, Golfo Pérsico, Golfo de Mannar o costa de la India). Todos estos datos indican que estamos ante un taller con fácil acceso a este tipo de materias primas, probablemente a través de talleres lapidarios que a su vez contaban con diversidad de recursos y de fuentes de abastecimiento.

El vidrio sintético jugó un papel secundario en Guarrazar, y se utilizó fundamentalmente como complemento de color. Los análisis elementales determinan que se trata de vidrios sódico-cálcicos y vidrios de silicato de plomo, lo que es evidencia de una baja cronología de uso de estos últimos, anteriormente considerada como más $\operatorname{tardía}^{35}$.

En Torredonjimeno las proporciones se invierten, documentándose en la muestra analizada un mayor número de vidrios y una menor diversidad de las gemas utilizadas. Se han identificado amatistas; esmeraldas; nácar; granates; cuarzos y zafiros. En este caso contamos con menos datos sobre la procedencia de estas gemas, coincidiendo la de dos esmeraldas con las minas de Habachtal ${ }^{36}$. Los vidrios sintéticos, que probablemente fueron empleados no como un complemento ornamental, sino para sustituir a las gemas, muestran mayor diversidad que los de Guarrazar, documentándose cuatro sistemas de composición: vidrios sódico-cálcicos, con contenidos medios o bajos de plomo; vidrios de silicato, y vidrios de silicato potásico-cálcico con óxido de plomo ${ }^{37}$.

\section{Los procesos de fabricación. El taller orfebre de Guarrazar}

Los estudios realizados en las fases topográfica y analítica han permitido caracterizar las principales técnicas de trabajo empleadas por los orfebres de Guarrazar y su comparación con Torredonjimeno. Como se aprecia en la Tabla 1, la mayor parte de las técnicas identificadas se manifiesta por igual en ambos conjuntos, incluyendo la de la soldadura, que constituyó el procedimiento básico para la unión entre los distintos elementos de las piezas. En ambos conjuntos, su aplicación se realizó mediante la interposición de un material de base $\mathrm{Au}-\mathrm{Ag}$ con menor punto de fusión entre las partes a unir, observándose una gran calidad de ejecución. El uso del dorado, documentado únicamente en Torredonjimeno, marca la diferencia principal en cuanto a los procedimientos utilizados, y como se ha señalado, ha servido para establecer importantes consideraciones para la interpretación de este hallazgo.

34 M.F. GUERRA et al., op. cit., 2007, p. 67.

35 J.S CÓZAR y C. SAPALSKI, op. cit., 2001, p. 269; T. CALLIGARO, J.C. DRAN y J.P. POIROT, op. cit., 2001, p. 285.

36 P.C. GUTIÉRREZ NEIRA et al., "Estudio PIXE y PIGE de gemas en el tesoro de Torredonjimeno", Actas del VII Congreso Ibérico de Arqueometría, Madrid, 2008, pp. 390-396; A. CLIMENT-FONT et al., op. cit., 2009, pp. 233 y ss.

37 A. CLIMENT-FONT, et al., op. cit., 2009, pp. 223 y ss. 


\begin{tabular}{|c|c|c|c|}
\hline FASE & TÉCNICA & Guarrazar & Torredonjimeno \\
\hline \multirow{4}{*}{$\begin{array}{l}\text { Preparación del material de base } \\
\text { (Láminas/Chapas; Hilos/Alambres) }\end{array}$} & Cortado & $\mathrm{X}$ & $\mathrm{X}$ \\
\hline & Martillado & $\mathrm{X}$ & $\mathrm{X}$ \\
\hline & Batido & $\mathrm{X}$ & $\mathrm{X}$ \\
\hline & Embutido & $\mathrm{X}$ & $\mathrm{X}$ \\
\hline \multirow{8}{*}{ Fabricación / ornamentación } & Cincelado & $\mathrm{X}$ & $\mathrm{X}$ \\
\hline & Calado & $\mathrm{X}$ & \\
\hline & Tabicado (cloisonné) & $\mathrm{X}$ & $X$ \\
\hline & Repujado & $\mathrm{X}$ & $\mathrm{X}$ \\
\hline & Estampado & & $X$ \\
\hline & Filigrana & $\mathrm{X}$ & $\mathrm{X}$ \\
\hline & Gránulos & $\mathrm{X}$ & $\mathrm{X}$ \\
\hline & Engastado & $\mathrm{X}$ & $\mathrm{X}$ \\
\hline Técnicas de unión & Soldadura & $\mathrm{X}$ & $\mathrm{X}$ \\
\hline \multirow{3}{*}{ Montaje/Acabado } & Enrasado & $\mathrm{X}$ & $\mathrm{X}$ \\
\hline & Pulido & $\mathrm{X}$ & $\mathrm{X}$ \\
\hline & Dorado & & $\mathrm{X}$ \\
\hline
\end{tabular}

Tabla 1. Principales técnicas de fabricación documentadas en Guarrazar y Torredonjimento, en función de las principales fases de trabajo.

\section{El trabajo con láminas y chapas}

Las coronas y las cruces de Guarrazar muestran buenos ejemplos de la capacidad de los orfebres para recurrir a diferentes soluciones en función del tamaño, el peso y la ornamentación de los objetos, desde piezas de estructura relativamente simple, hasta objetos de gran complejidad técnica, cuyo mejor exponente es la corona de Recesvinto.

En el grupo de las coronas, la de chapa simple de Cluny es la de estructura más sencilla. Su banda está formada por un cilindro simple dividido en dos mitades unidas por charnelas (Fig. 6, 2), cuyos bordes se reforzaron hacia el interior con una cinta laminar soldada. El exterior de la diadema está decorado con tres bandas paralelas de engastes con cabujones, que se distribuyen en aparente desorden en cuanto a sus formas y colores. En los bordes superior y exterior del cilindro se disponen tramos de hilos moldurados soldados que imitan esferillas (Fig. 6, 1). Por su tamaño y pureza de composición, esta pieza podría interpretarse como una corona real, aunque carece de las fórmulas de dedicación que caracterizan a los ejemplares de Recesvinto o Suintila. La sencillez de su estructura y técnica ornamental podría sugerir igualmente su mayor antigüedad respecto al resto de las piezas del conjunto.

Otro ejemplo de las soluciones desarrolladas por los orfebres de Guarrazar son las coronas de estructura reticulada, exclusivas de este conjunto, de las que hoy conservamos cuatro ejemplares muy semejantes. Su fabricación parte de una sola pieza laminar en forma de cilindro, que se recorta mediante martillo y cincel para formar una retícula, soldándose sobre los tramos rectos láminas embutidas en forma de huso, y sobre las intersecciones, los engastes, alternando cabujones circulares y cuadrangu- 
lares (Fig. 6, 3). La fragilidad de la estructura de estas coronas ha provocado roturas, que en muchos casos fueron reparadas en el s. XIX con soldaduras de plomo-estaño (Fig. 4, 2), o laminillas de oro de refuerzo. La aplicación de láminas de refuerzo se ha identificado también en una reparación antigua del ejemplar del museo de Cluny (Fig. 6, 4) ${ }^{38}$.

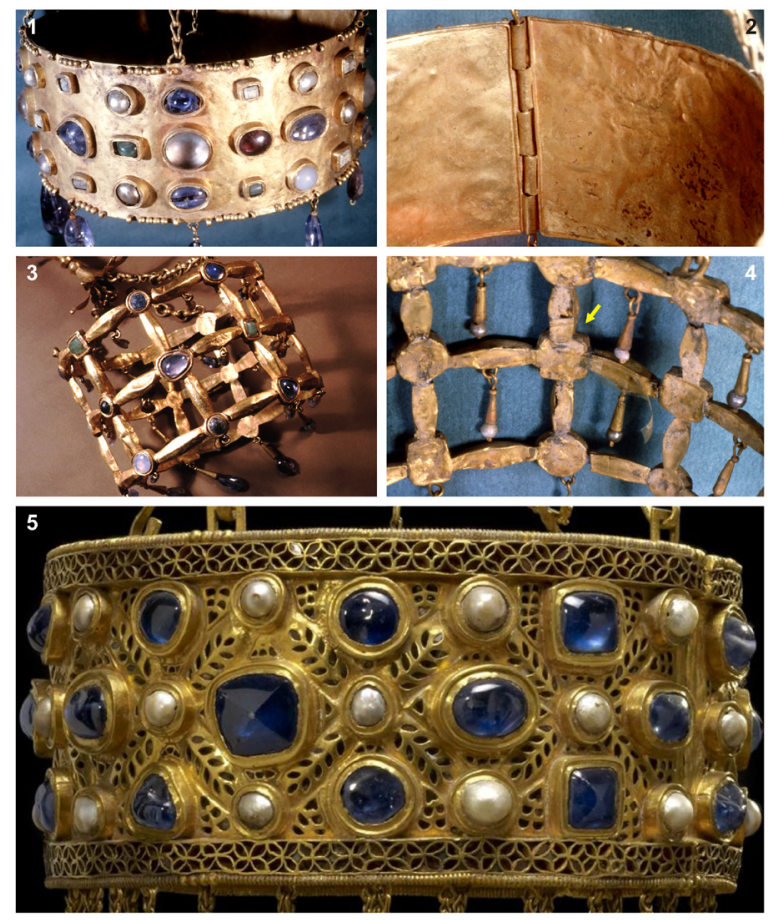

Fig. 6. Trabajo con láminas y chapas en las coronas de Guarrazar: 1 y 2. Corona de chapa laminar de Cluny: 1. Detalle de la banda; 2 detalle del interior liso y del sistema de unión por charnelas; 3 y 4 . Coronas de estructura reticulada: 3 . Aspecto general exterior en uno de los ejemplares (MAN 71207); 4. Detalle del interior de otro ejemplar (Cluny 3211), con un ejemplo de reparación antigua por adición de láminas de refuerzo; 5 . Banda de la corona de doble chapa de Recesvinto (MAN 71202). Fotos: Archivo Au (1 a 4), MECD (5).

La corona de Recesvinto (Fig. 6, 5), a la que nos referiremos frecuentemente, constituye el ejemplar de mayor complejidad estructural del conjunto, y es el mejor exponente de los conocimientos técnicos y de la capacidad organizativa del taller de Guarrazar. La estructura cilíndrica de la diadema es doble y se elaboró en dos mitades que se unen entre sí mediante charnelas. El cilindro interior es liso, el exterior incorpora una decoración calada, cincelada y repujada, con engastes y cabujones dispuestos en "5 de dados". Originalmente, todos los espacios calados fueron incrustados

38 A. PEREA, "De los talleres y los orfebres. La tecnología del oro”, A. PEREA (ed.), op. cit., 2001, pp. 152 y 154. 
con granates. Los bordes del cilindro se decoraron con una cenefa de rosetas tabicadas incrustadas, que se rematan con hilos moldurados. A excepción de éstas, el patrón ornamental del cilindro de la corona es muy similar al observable en los brazos de la cruz procesional, pieza que consideramos como su modelo de inspiración (vid. infra).
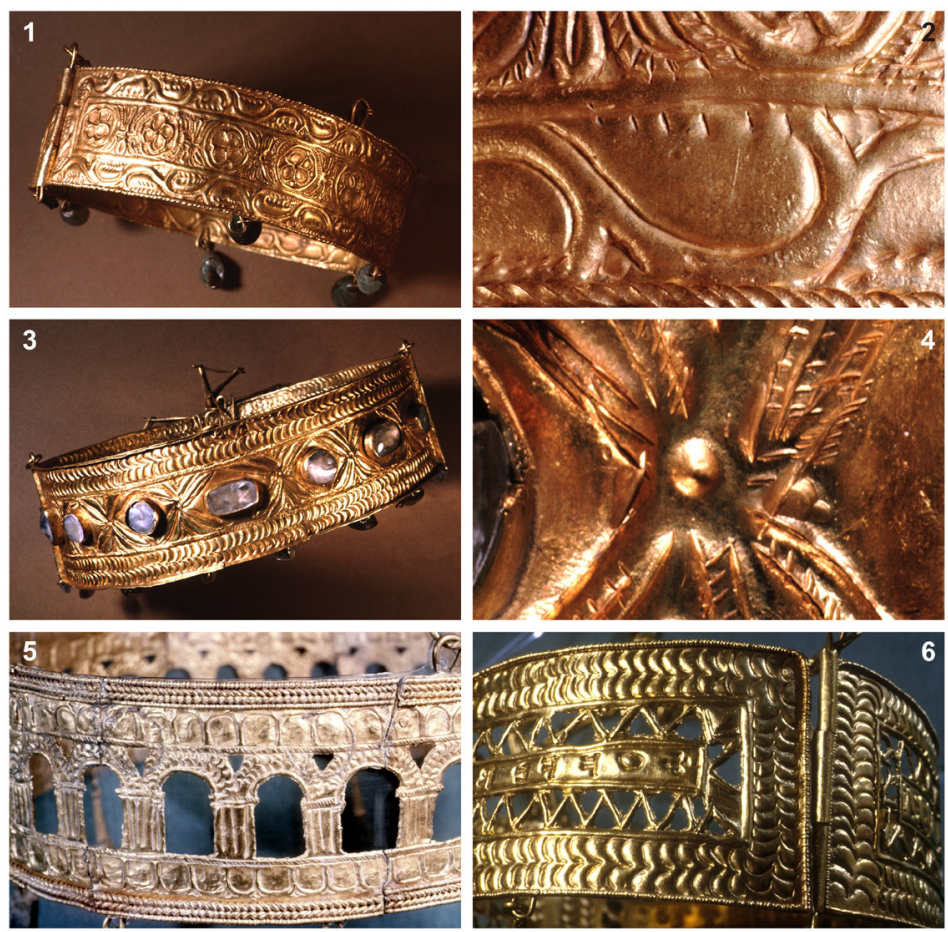

Fig. 7. Coronas de lámina repujada de Guarrazar: 1-2. Corona sin engastes (MAN 71205). Aspecto de la banda y detalle de la decoración; 3-4. Corona con engastes (MAN 71204). Aspecto de la banda y detalle de la ornamentación; 5. Corona con arcos (M. Cluny 2885), detalle de la ornamentación, apreciándose reparaciones y deterioros. 6. Corona de Teodosio (P. Real 10012363), detalle de decoración. Se observan rebabas de corte en las zonas reticuladas que bordean la inscripción. Fotos: Archivo Au.

\section{Repujado y Cincelado}

El repujado y el cincelado son dos técnicas que adquieren una especial relevancia en la decoración de los objetos de Guarrazar y Torredonjimeno. En Guarrazar, el mejor ejemplo lo constituyen las cuatro coronas de lámina repujada repartidas entre el MAN, Cluny y el Palacio Real. La corona sin engastes (MAN 71205), ofrece un excelente trabajo de repujado y cincelado, que simula una labor de brocado con motivos vegetales (Fig. 7, 1-2). La corona con engastes (MAN 71206), cuyo patrón ornamental es más simple, muestra sin embargo una ejecución descuidada, documentándose numerosos fallos de trabajo (Fig. 7, 3-4). La comparación de ambos ejempla- 
res evidencia el trabajo de distintos artesanos. También se observan diferencias entre las coronas de Cluny y del Palacio Real (corona de Teodosio), que combinan el repujado con el recorte de las láminas. El ejemplar del Palacio Real presenta una buena ejecución del repujado, pero numerosas rebabas e imperfecciones en el recorte (Fig. $7,6)$. El de Cluny incorpora un repujado de menor calidad, pero una decoración más elaborada, incluyendo una decoración recortada de tipo arquitectónico. Originalmente incorporaba también engastes, actualmente perdidos (Fig. 7, 5, véase y Fig. 4, 1).
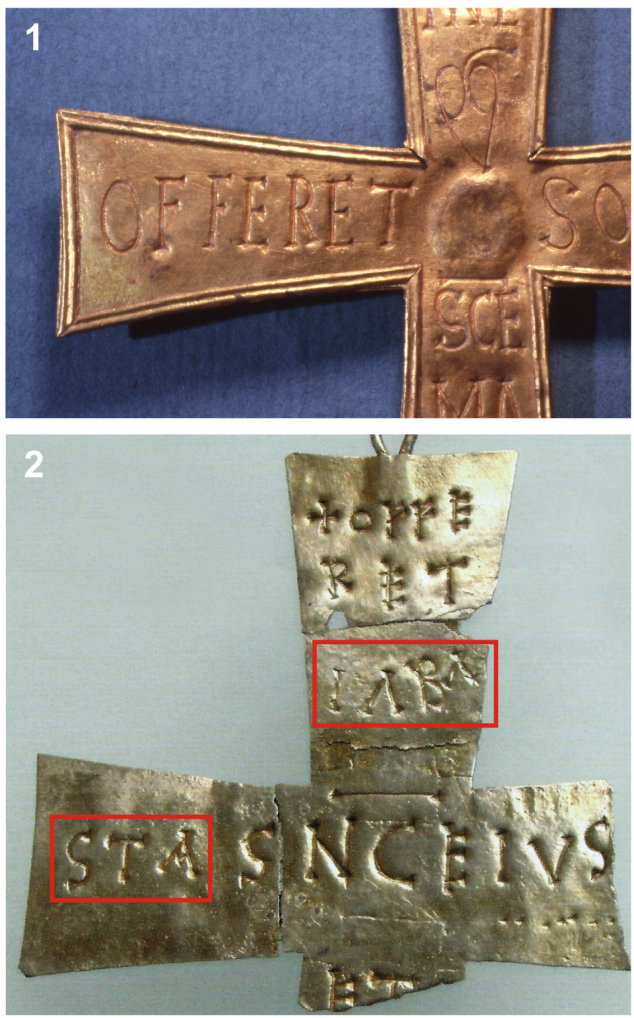

Fig. 8. 1. Guarrazar. Detalle de la inscripción de la cruz de Sonnica (M. Cluny 2879); 2. Torredonjimeno. Inscripción con dos grafías en la cruz de IABASTA (MAC 25.077/25.250 y MAECO 29932/30076). Fotos: Archivo Au.

Las tres inscripciones documentadas en Guarrazar, incluidas en la corona de Teodosio y en las cruces de Lucecio y Sonnica (Fig. 8, 1), también se realizaron mediante cincelado "a mano alzada" y ofrecen diferentes calidades de ejecución, no documentándose el uso de estampillas para su ejecución. La misma característica se observa también en las numerosas inscripciones de Torredonjimeno, donde el estampado sobre lámina sí se ha documentado. Las inscripciones de este conjunto evidencian el trabajo de distintos artesanos y en algún caso parecen indicar una mayor estandariza- 
ción en sus producciones. Un ejemplo lo constituye una cruz (MAC n ${ }^{\circ}$ 25077/25350 y MAECO ${ }^{\circ}$ 29933/30076), en la que el nombre del dedicante -IABASTA- se añadió con una grafía distinta, ocupando un espacio en blanco (Fig. 8,2).

Otras técnicas y procedimientos documentados en las piezas de Guarrazar nos informan de las influencias tecnológicas de este taller, y evidencian la importancia de la tradición tecnológica de la Antigüedad en la orfebrería de este período.

\section{El calado con incrustación}

El calado con incrustación está presente en la desaparecida corona de Suintila, en la corona de Recesvinto (vid. Fig. 6, 5), y en los brazos de la gran cruz procesional.
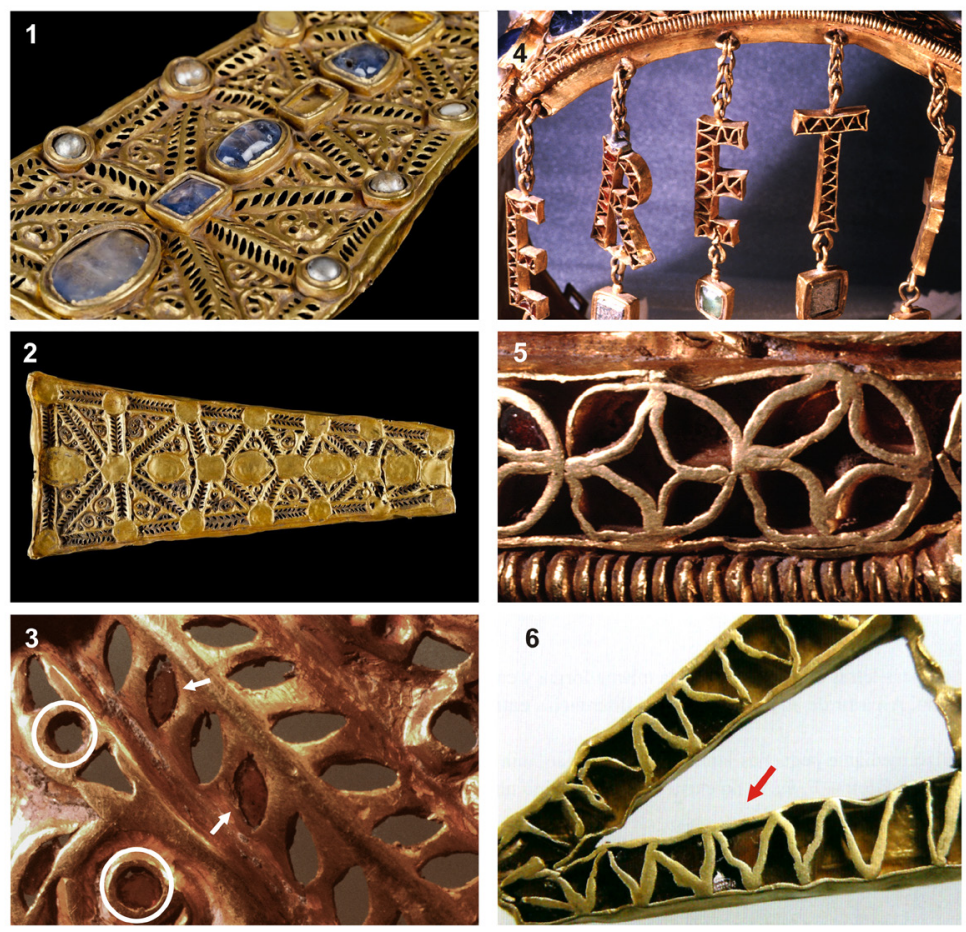

Fig. 9. Fotos 1 a 3: calado e Incrustación en los brazos de la gran cruz procesional de Guarrazar (MAN 52561): 1. Detalle de calado y engastes, anverso; 2. Detalle del trabajo por el reverso; 3. Detalle del reverso, apreciándose las marcas del uso de punzones circulares, e incrustaciones de granates in situ, Reverso. Fotos 4 a 6: Incrustación por tabicado (cloisonné) en Guarrazar: 4. Letras tabicadas de la corona de Recesvinto; 5. Detalle de la cenefa tabicada del borde inferior de esta corona. 6. Tabicado en Torredonjimeno: detalle del cuerpo de una letra V tabicada, que conserva un granate (MAC 25098). Fotos Archivo Au, MECD (1 y 2).

El patrón ornamental de esta cruz, muy semejante al de la corona de Recesvinto, se articula mediante bandas en relieve, que incluyen pequeños motivos calados en 
forma de hoja, cuyos extremos delimitan el espacio para los engastes. Los bordes de la chapa se reservaron para los engastes circulares con cabujones blancos, y la zona central para los cabujones de color. Los espacios entre las bandas incluyen figuras de roleos con calados de motivos triangulares y circulares (Fig. 9, 1). Todos los motivos calados fueron incrustados con granates, de los que hoy solo se conservan algunos (Fig. 9, 3).

Las chapas se repujaron desde el reverso para dar volumen (Fig. 9, 2). Posteriormente, se recortaron a punzón y a cincel desde el anverso. Por sus características tecnológicas ${ }^{39}$, podríamos interpretar esta cruz como una de las piezas más antiguas del tesoro, fechable en torno al s. VI, y ajena al taller de Guarrazar. Probablemente fue una cruz de especial veneración fabricada en un taller extrapeninsular, que pudo haber sido enviada a Toledo como regalo regio. Por esta circunstancia, sirvió como modelo para la elaboración de la corona de Recesvinto, y para la de Suintila ${ }^{40}$.

\section{Incrustación por tabicado (cloisonné)}

Constituye otro procedimiento antiguo, de origen oriental, que se extendió hacia el occidente europeo durante el período de las migraciones, y que llegó a caracterizar el estilo polícromo de la orfebrería de los pueblos germánicos, conociendo un mayor apogeo entre los siglos $\mathrm{V}$ y VI ${ }^{41}$. Consiste básicamente en la soldadura de pequeños tabiques de oro que se disponen en ángulo recto sobre la lámina de base, o al aire. Estos tabiques se sueldan entre sí para crear un patrón ornamental a base de celdillas, que generalmente forman una serie de motivos geométricos repetidos. En estas celdillas, se colocan posteriormente las incrustaciones, generalmente de granates, lográndose un efecto ornamental por contrastes de color.

En Guarrazar, este procedimiento está documentado en las letras de dedicación de las coronas de Suintila y de Recesvinto (Fig. 9, 4), y en los extremos superior e inferior de la cenefa de rosetas entrelazadas de la banda de esta última (Fig. 9, 5). En Torredonjimeno, se empleó en las cruces de pequeño tamaño, en algún fragmento de interpretación funcional dudosa, y especialmente en los colgantes con forma de letra, en los que se conserva algún granate (Fig. 9, 6).

\section{El trabajo con hilos}

El estudio de los hilos utilizados en Guarrazar pone de manifiesto la continuidad de este taller con la tradición orfebre de la Antigüedad ${ }^{42}$. Se elaboraron mediante la técnica del hilo torsionado, a partir de una fina lámina que se enrolla sobre sí misma hasta formar un tubo, hueco o compacto (Fig. 10, A). Esta operación deja sobre su

39 El recortado y perforación de láminas desde el anverso para formar un motivo ornamental en reserva fue una característica de la orfebrería romana desde el s. II (técnica de opus interrasile), perdurando hasta los siglos IV-V, siendo progresivamente sustituidos por la técnica del cortado a cincel.

40 Sobre la interpretación de este objeto véase A. PEREA, op. cit., 2001, pp. 199-200.

41 B. ARRHENIUS, Merovingian Garnet Jewelry. Emergence and social implications, Göteborg, 1985.

42 A. PEREA, "Visigothic filigree in the Guarrazar (Toledo) and Torredonjimeno (Jaén) treasures", Historical Metallurgy, 40, 1 (2006), pp. 1-11. 
superficie una característica huella helicoidal, con helicoides más o menos cerrados en función del grado de torsión a la que fuese sometida, y de su grosor inicial. Este procedimiento, que hace posible elaborar hilos muy finos que no podrían obtenerse a partir de martillado, está documentado en la orfebrería prehistórica del Próximo Oriente y del Mediterráneo al menos desde el II milenio a.C., y tuvo continuidad hasta la invención de la hilera, en una fecha que todavía se discute, pero que probablemente debe situarse hacia los siglos XI-XII d.C.
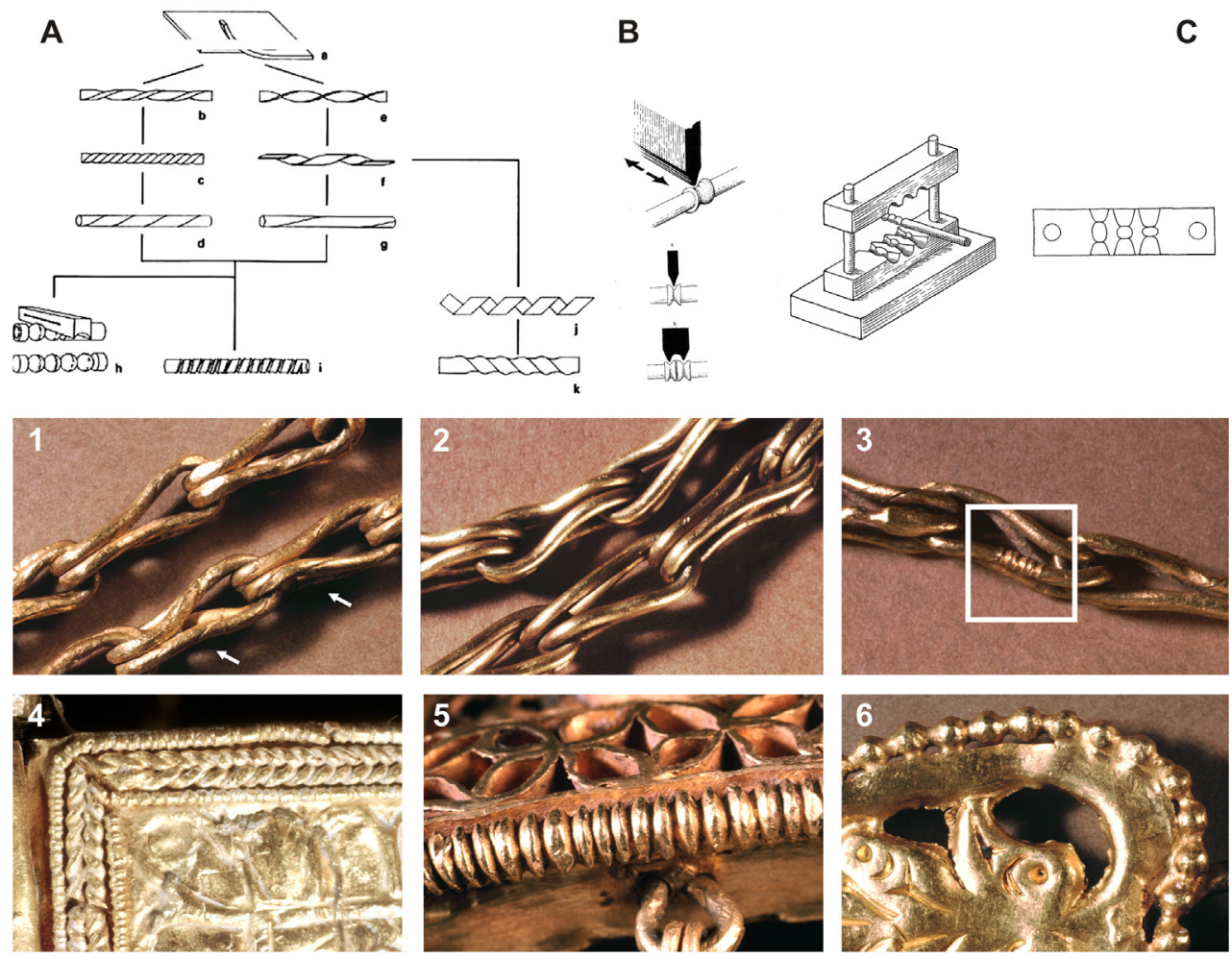

Fig. 10. Trabajo con hilos. A. Esquema de elaboración de hilos con la técnica del hilo por torsión; B. Esquema del sistema de uso de herramientas de filo cortante para la elaboración de hilos moldurados; C. Ejemplo de uso del Organarium. 1. Detalle de los eslabones de la cadena loop-in-loop de la cruz de la corona de Recesvinto, elaborados con la técnica del hilo por torsión. Las flechas indican las huellas helicoidales de la superficie del hilo que definen este procedimiento; 2. Ejemplo de sustitución de eslabones con hilos modernos fabricados en hilera, en la misma cadena; 3. Hilo que se trabajó en parte con una herramienta de filo cortante, y fue posteriormente reutilizado para la fabricación de uno de los eslabones de la cadena de la pieza anterior; 4. Detalle de los hilos torsionados y moldurados -al interior y exterior de la serie- en la banda de la corona repujada de Cluny; 5. Hilo moldurado en el borde inferior de la corona de Recesvinto; 6. Detalle del hilo moldurado que bordea uno de

los eslabones laminares de la cadena de la corona de Recesvinto. Fotos: Archivo Au. 
La técnica del hilo torsionado se utilizó por ejemplo en la elaboración de las cadenas de tipo loop-in-loop (Fig. 10, 1), también documentadas en el conjunto de Torredonjimeno. Estas cadenas conectan la tecnología del taller de Guarrazar con una tradición orfebre mediterránea de gran antigüedad, documentándose su uso en la orfebrería prehistórica peninsular al menos desde los siglos VI-V a.C $\mathrm{C}^{43}$.

Parte de las cadenas originales de Guarrazar se perdieron o deterioraron tras el hallazgo, y fueron sustituidas a finales del s. XIX por imitaciones, empleándose para ello hilos fabricados en una hilera mecánica. Estas sustituciones han podido identificarse en el estudio con lupa binocular, pues el uso de esta herramienta deja sobre la superficie de los hilos una característica huella lineal (Fig. 10,2).

Los hilos trabajados, como los que rematan los bordes de algunas coronas también fueron fabricados con la técnica de la torsión, aunque se trabajaron posteriormente con una herramienta de filo simple o doble, con la que se presiona el hilo, haciéndolo rodar sobre una superficie horizontal (Fig. 11, B). Con este procedimiento, que también cuenta con buenos ejemplos en la orfebrería prehistórica del Mediterráneo, se fabricaron por ejemplo algunos de los hilos que bordean la corona repujada de Cluny (Fig. 10,4). Otra prueba del uso de estas herramientas está en un eslabón cuya superficie comenzó a trabajarse, abandonándose después (Fig. 10,3). Este hilo proporciona también una interesante información sobre el taller de Guarrazar, y confirma la importancia del reciclado como parte de los modos de trabajo ${ }^{44}$.

Finalmente, se documentan ejemplares más elaborados y complejos, que parecen implicar el uso de otros procedimientos. Una herramienta que probablemente ya existió en estos momentos fue el organarium, y que al igual que las de filo simple anteriores fue descrito por el monje Theophilus en su obra De Diversis Artibus, hacia el año 1140. Se trata de una especie de prensa que incorpora en su superficie molduras en hueco, por las que se induce el hilo liso para estamparlo (Fig. 10, C) ${ }^{45}$. Con el organarium podrían haberse obtenido, por ejemplo, los hilos que rematan la banda de la corona de Recesvinto (Fig. 10, 5), o los que bordean los eslabones laminares de su cadena (Fig. 10, 6).

\section{El color, gemas, engastes y cabujones}

Las piezas de Guarrazar transmiten unos códigos simbólicos que se reflejan tanto en sus formas como en su ornamentación. El color y su disposición parecen constituir unos aspectos muy importantes para la expresión de este mensaje, condicionando en buena medida la decoración de los objetos. Por ejemplo, en la mayor parte de las cruces laminares de Guarrazar, los chatones blancos (perlas y nácar) presentan formas circulares y se reservan para los extremos de los brazos, quedando los chatones de

43 Véase p.e. J.R. REIST y J. REIST, Classical loop-in-loop chains, Londres, 2007. Sobre su uso en la orfebrería prerromana peninsular ver p.e. A. PEREA, Orfebrería Prerromana, Arqueología del oro, Madrid, 1991.

44 A. PEREA, op. cit., 2001, p. 182.

45 N. WHITFIELD, "The manufacture of beaded wire in the post-roman period", A. PEREA, I. MONTERO-RUIZ y O. GARCÍA-VUELTA (eds.), op. cit., 2004, pp. 128-131. 
color, con formas más irregulares y generalmente de tamaño algo mayor, en la parte central (Fig. 11, 1). Observamos una disposición similar en los brazos de la cruz procesional, así como en la cruz de Recesvinto. Las diferencias entre el color blanco y el resto de los elementos parece jugar también un papel importante en la decoración de las coronas, como sugiere la distribución en forma de " 5 de dados" de los chatones del ejemplar de Recesvinto (Fig. 11,2). Estas características enlazan con la tradición de la orfebrería bizantina ${ }^{46}$, aunque en Guarrazar también encontramos excepciones, como vemos en la decoración de la banda de la corona de chapa simple de Cluny (vid. Fig. 6, 1).
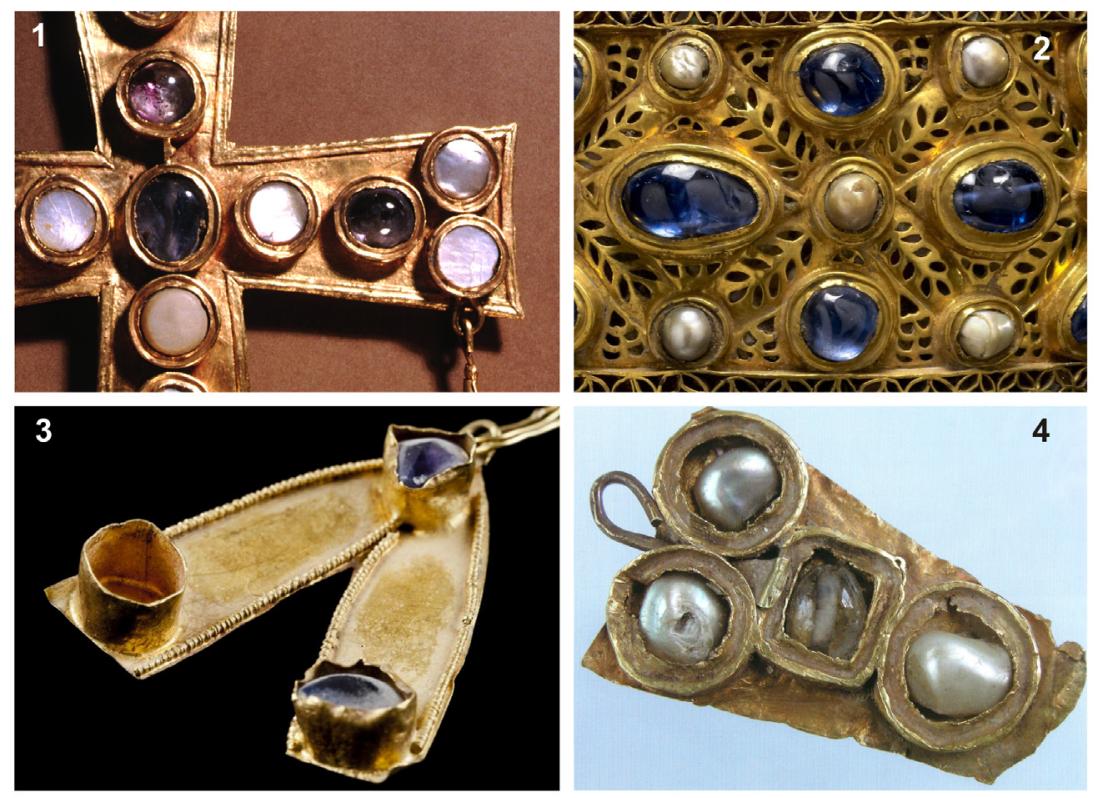

Fig. 11. Guarrazar 1. Detalle de la disposición de los chatones en la cruz laminar con colgantes largos del MAN (71210); 2. Disposición de los chatones en 5 de dados en la corona de Recesvinto, con engastes de tipo cápsula; 3. Engastes de bata simple en el colgante en Alfa (MAN 52560); 4. Torredonjimeno. Engastes circulares de tipo cápsula y engaste cuadrangular de tipo caja en el brazo de una cruz incompleta (MAECO 29926). Fotos: Archivo Au, MECD (3).

Los engastes ofrecen una especial importancia como elemento de soporte de estos códigos de color. Todos ellos manifiestan una cuidada elaboración, que podemos observar también en los que incorporan las piezas de Torredonjimeno.

En Guarrazar, predominan los engastes de tipo cápsula con moldura (Fig. 11, 1-2), elaborados mediante el embutido de una lámina, que posteriormente se recorta para

46 Ver un comentario sobre estas cuestiones en H. SCHLUNK, Las cruces de Oviedo. El culto de la Vera Cruz en el Reino Asturiano, Oviedo, 1985, o A. PEREA, op. cit., 2001, pp. 196-197. 
crear el hueco en el que se sitúa el cabujón, repasándose posteriormente a cincel. En menor medida, el conjunto incorpora también piezas con engastes de bata simple, de paredes lisas y borde superior abatido hacia el interior, como la corona repujada con cabujones, o el colgante con letra Alfa o del MAN (Fig. 11, 3). En Torredonjimeno esta proporción se invierte, con un predominio de los engastes de bata simple. Sin embargo, encontramos también ejemplos de engastes más elaborados, incluyendo un tipo no documentado en Guarrazar, los engastes en caja, fabricados mediante la soldadura de varios cuerpos laminares, que como los de tipo cápsula, pudieron reservarse para las piezas de mayor calidad técnica (Figura 11,4) .

Los engastes de la cruz de estructura calada de la corona de Recesvinto (Fig. 12) constituyen un caso aparte. Tienen forma de templete con columnas vegetales, cuyo capitel termina en unas patillas que sirven para sujetar a los zafiros (Fig. 12, derecha). Las perlas situadas en los extremos de los brazos se sujetan mediante un hilo de oro enfilado por una perforación que las atraviesa, un sistema que al igual que los engastes anteriores, está bien documentado la orfebrería bizantina. Sin duda, y a pesar de su asociación de origen a la corona de Recesvinto, nos encontramos ante una pieza tecnológicamente diferente y ajena al taller de Guarrazar, quizá elaborada por un orfebre bizantino, como ya se ha sugerido
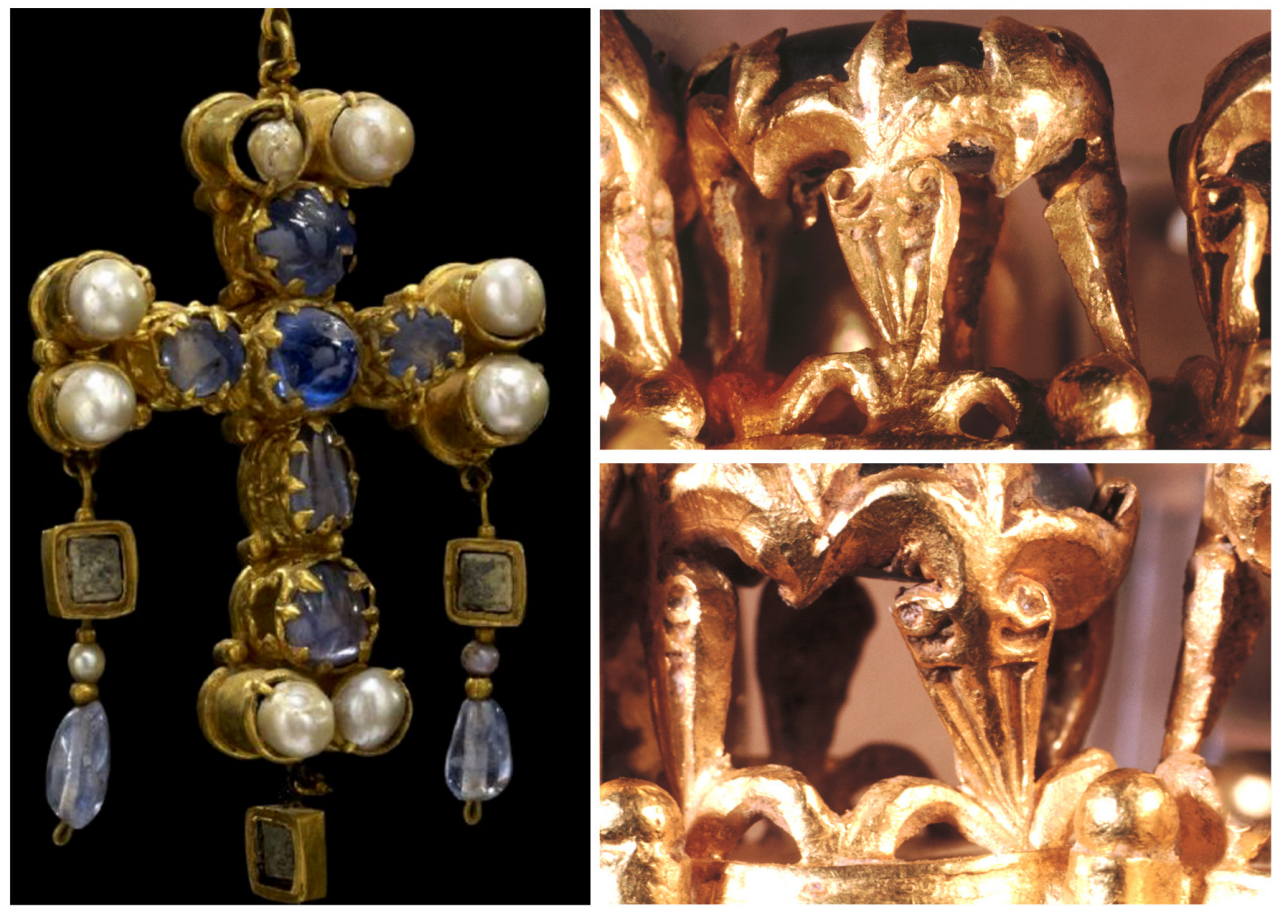

Fig. 12. Cruz de la corona de Recesvinto. Detalle de la estructura y ornamentación del cuerpo por el anverso, y detalles de los engastes elevados que sujetan los zafiros. Fotos: Archivo $\mathrm{Au}, \mathrm{MECD}$. 


\section{El proceso de producción}

Las piezas de Guarrazar corresponden a un taller de tipo palacial, estable y bien organizado, que debemos valorar desde una perspectiva diacrónica, pues en este participaron diferentes artesanos a lo largo del tiempo.

Este taller asumió la producción tanto de piezas tecnológicamente simples como de objetos con una gran complejidad. Tanto unos como otros, implicaron el control y la gestión de un proceso complejo, que se inicia antes de la fabricación del objeto, y que abarca desde su diseño hasta el cálculo de las materias primas, técnicas, herramientas y tiempo de trabajo necesario (unas 500 horas, en el caso de la corona de Recesvinto); además de los procesos de elaboración y montaje. El estudio de los objetos ha mostrado igualmente la capacidad de estos orfebres para aplicar diferentes soluciones técnicas en función de sus características (tamaño, peso o complejidad estructural u ornamental).

Los orfebres de Guarrazar contaron con un fácil acceso tanto a los recursos metálicos -suministrados por el propio palacio o los personajes demandantes de los objetos- como a los gemológicos, a través de talleres lapidarios que lo abastecerían en función de las necesidades de cada momento. Contarían igualmente con unas instalaciones que incluirían toda la infraestructura necesaria para el desarrollo de su actividad. Por ejemplo, al menos dos hornos, uno grande y uno pequeño, avivados con fuelles para el control de su temperatura, en los que se prepararían las aleaciones y se ejecutarían los procesos térmicos de trabajo, incluyendo las soldaduras ${ }^{47}$. La instalación contaría también con bancos de trabajo; distintos tipos de yunques para el forjado o trabajado de láminas, chapas y alambres; y herramientas de filo cortante o prensas para el trabajo con hilos. Junto a lo anterior, encontraríamos el amplio conjunto de herramientas y materiales empleados en las diferentes fases de trabajo: crisoles, lingoteras, material refractario de apoyo, pinzas o tenazas para manipular los objetos en el fuego, martillos de diferentes tipos; embutidores; compases para trazar; taladros, punzones y cinceles; materiales adhesivos; de cementación, abrasivos para el acabado final de los objetos (p. ej. cuero, arena o cenizas), etc. Seguramente, el orfebre dispondría también en esta oficina de una pequeña reserva de metal semielaborado o fragmentado, así como de gemas y vidrios procedentes de objetos ya desechados, dispuestos para su reciclaje.

Como ya se ha señalado, las producciones del taller de Guarrazar estuvieron condicionadas por unos códigos ritualizados en función del tipo de pieza a elaborar o de la naturaleza de los encargos recibidos. Tanto estos códigos como los conocimientos técnicos se transmitirían de generación a generación entre los orfebres, contribuyendo a dificultar la valoración de las diferencias cronológicas o tecnológicas entre sus materiales.

47 El uso en estos momentos de herramientas para direccionar la llama, como el soplete, constituye un tema abierto. Sobre esta cuestión véase A. PEREA, op. cit., 2001, p. 195. 


\section{Valoración final}

La singularidad de las piezas conservadas y las distintas calidades técnicas documentadas en Guarrazar sugieren que nos encontramos ante un conjunto heterogéneo. Podemos diferenciar, al menos, dos talleres o momentos diferentes. Un taller antiguo, cuya fecha no puede determinarse con exactitud, pero que es anterior al reinado de Suintila (621-631), al que atribuimos la corona de chapa simple del museo de Cluny. En segundo lugar un taller reciente, al que corresponde la mayor parte de los objetos del conjunto y que cuenta con dos marcadores cronológicos fundamentales: los reinados de Suintila y Recesvinto (649-672). Entre ambos talleres, deberíamos situar la gran cruz procesional, procedente de un taller externo y probablemente fechable hacia el s. VI, a partir de la cual se fabricará la corona de Recesvinto.

Respecto a la comparación con Torredonjimeno, las identidades formales y tecnológicas observables permiten defender su coetaneidad con el taller reciente de Guarrazar, ${ }^{48}$ aunque sus producciones puedan abarcar un espacio temporal más amplio $^{49}$.

La tecnología de Guarrazar y Torredonjimeno debe valorarse principalmente en el entorno de la tecnología mediterránea de la Antigüedad, aunque pueda también reflejar otras influencias posteriores. Desde el punto de vista tecnológico, la gran aportación de Guarrazar a la historia de la orfebrería son los complejos procesos de producción asociados a la fabricación de estas cruces y coronas.

A pesar de las similitudes formales, ambos conjuntos son muy diferentes. Guarrazar debe enmarcarse en el ámbito de un taller palacial de uso real y aristocrático. Por el contrario, Torredonjimeno refleja el trabajo de varios talleres, con unas producciones que -al menos en su mayor parte- estuvieron destinadas a un espectro social más amplio. Tampoco las circunstancias de ambas ocultaciones son comparables. El cuidadoso ocultamiento del conjunto de Guarrazar entra en contradicción con el troceado y doblado de las piezas de Torredonjimeno, realizado probablemente para poder ocultar las piezas en el menor espacio posible, lo que caracterizaría el fruto de un expolio.

Las conclusiones de los trabajos realizados muestran la conveniencia de integrar el estudio tecnológico y arqueométrico de este tipo de materiales como una parte importante de la metodología de su investigación. Ambos enfoques permiten sin duda resolver diferentes cuestiones de tipo técnico, sin embargo, deben ser principalmente valorados como fuente de información a diferentes niveles (cronológico, social, económico, simbólico), una información no necesariamente orientada a resolver, sino a sugerir nuevos caminos de interpretación. Consideramos que las aportaciones realizadas desde el Proyecto Guarrazar han supuesto un buen ejemplo en ese sentido.

48 A. PEREA, "Estudio comparativo entre los tesoros de Guarrazar y Torredonjimeno", A. PEREA (ed.), op. cit., 2009, pp. 183-186.

49 A. PEREA, "Un taller de orfebrería visigodo en la Bética", A. PEREA (ed.), op. cit., 2009, pp. 187-194. 